\title{
Influence of cholesterol and its stereoisomers on members of the serotonin receptor family
}

\author{
Victoria Oakes ${ }^{1}$ and Carmen Domene $e^{1,2^{*}}$ \\ ${ }^{1}$ Department of Chemistry, University of Bath, Claverton Down, Bath, BA2 7AY, UK \\ ${ }^{2}$ Department of Chemistry, University of Oxford, Oxford, OX1 3TA, Oxford, UK
}

*Corresponding author: C.Domene@ bath.ac.uk Tel: +44 - (0)1225-386172

Running title: Influence of cholesterol on GPCRs.

Keywords: GPCRs; membrane proteins; protein-lipid interactions; stereospecificity; molecular dynamics simulations

\begin{abstract}
Despite the ubiquity of cholesterol within the cell membrane, the mechanism by which it influences embedded proteins remains elusive. Numerous GPCRs exhibit dramatic responses to membrane cholesterol, with regards to the ligand-binding affinity and functional properties, including the 5-HT receptor family. Here, we use over $25 \mu$ s of unbiased atomistic MD simulations to identify cholesterol interaction sites in the 5- $\mathrm{HT}_{1 \mathrm{~B}}$ and $5-\mathrm{HT}_{2 \mathrm{~B}}$ receptors and evaluate their impact on receptor structure. Susceptibility to membrane cholesterol is shown to be subtype-dependent and determined by the quality of interactions between the extracellular loops. Charged residues are essential to maintain the arrangement of the extracellular surface in $5-\mathrm{HT}_{2 \mathrm{~B}}$; in the absence of such interactions, the extracellular surface of the 5$\mathrm{HT}_{1 \mathrm{~B}}$ is malleable, populating a number of distinct conformations. Elevated-cholesterol density near transmembrane helix 4 is considered to be conducive to the conformation of extracellular loop 2 . Occupation of this site is also shown to be stereospecific, illustrated by differential behaviour of natcholesterol isomers, ent- and epi-cholesterol. In simulations containing the endogenous agonist, serotonin, cholesterol binding at transmembrane helix 4 biases bound serotonin molecules towards an unexpected binding mode in the extended binding pocket. The results highlight the capability of membrane cholesterol to influence the mobility of the extracellular surface in the 5-HT 1 receptor family and manipulate the architecture of the extracellular ligand-binding pocket.
\end{abstract}




\section{INTRODUCTION}

G-protein coupled receptors (GPCRs) play a fundamental role in the transmission of extracellular stimuli to the cell interior, participating in a broad spectrum of physiological processes being the most prominent target of clinically approved drugs. ${ }^{1}$ GPCRs are seven-helix transmembrane proteins (TM1-7), which can exist in a variety of conformational states. The evolution of active, inactive and intermediate states is promoted by small-molecule binding in the core of the transmembrane bundle, typically accessible from the extracellular medium. Activating ligands, known as agonists, stabilize conformations capable of Gprotein coupling, eliciting a response within the cell.

In recent years, membrane composition has emerged as an important factor in the drug-binding properties of GPCRs. Cholesterol, ${ }^{2}$ sphingolipids ${ }^{3}$ and phospholipid ${ }^{4}$ have been shown to modulate the activity of GPCRs; the ligand-binding affinity is a crucial property that can be regulated by cholesterol in both positive and negative manners. ${ }^{5-7}$ However, the mechanism by which cholesterol modulates protein structure and function is largely unknown. ${ }^{8}$ One theory suggests cholesterol acts by varying the physical properties of the membrane, which then influences the conformation of the protein. An alternative rationale proposes that cholesterol binds directly to specific sites on the protein surface, acting as an allosteric modulator. A third proposition suggests that cholesterol facilitates interactions with a third party which biases the activation state. Of course, the possibility also exists that these effects are not mutually exclusive, and a combinatory approach occurs.

Cholesterol exhibits an asymmetric structure formed from the isooctyl chain planar attached to the rigid polycylic sterane backbone. The latter comprises a smooth $\alpha$ face and rough $\beta$ face, and a polar hydroxyl moiety at the apex. A single cholesterol isomer occurs naturally, although eight stereocenters exist in the molecule (Scheme 1). Biological systems are capable of discriminating between stereoisomers of substrates and can therefore be classified as stereospecific. This is typically discussed in terms of enzyme catalysis. However, this trait has been established for various membrane proteins, regarding both agonists and allosteric modulators, such as membrane cholesterol. Subsequently, cholesterol isomers have emerged as valuable probes to distinguish between specific and non-specific effects of cholesterol in membrane proteins, and to scrutinize the level of specificity required action. ${ }^{9}$ Epi-cholesterol, which bears a distinct orientation of the hydroxyl group (Scheme 1), has been used widely, on the basis it forms analogous structured lipid domains ${ }^{10}$ and induces a similar level of membrane fluidity. ${ }^{11}$ However, other properties, such as the area per lipid and cholesterol tilt angle, are known to diverge, ${ }^{12}$ hence it is possible that both direct and indirect mechanisms of cholesterol are involved in modulation by epi-cholesterol. For this reason, it has been somewhat superseded by ent-cholesterol, the enantiomer of cholesterol (Scheme 1), which is considered to mimic the physiochemical membrane properties more closely. ${ }^{13}$ Experiments utilizing these analogues have successfully implicated stereospecific binding of cholesterol in the regulation of various membrane proteins. ${ }^{14-19}$ 


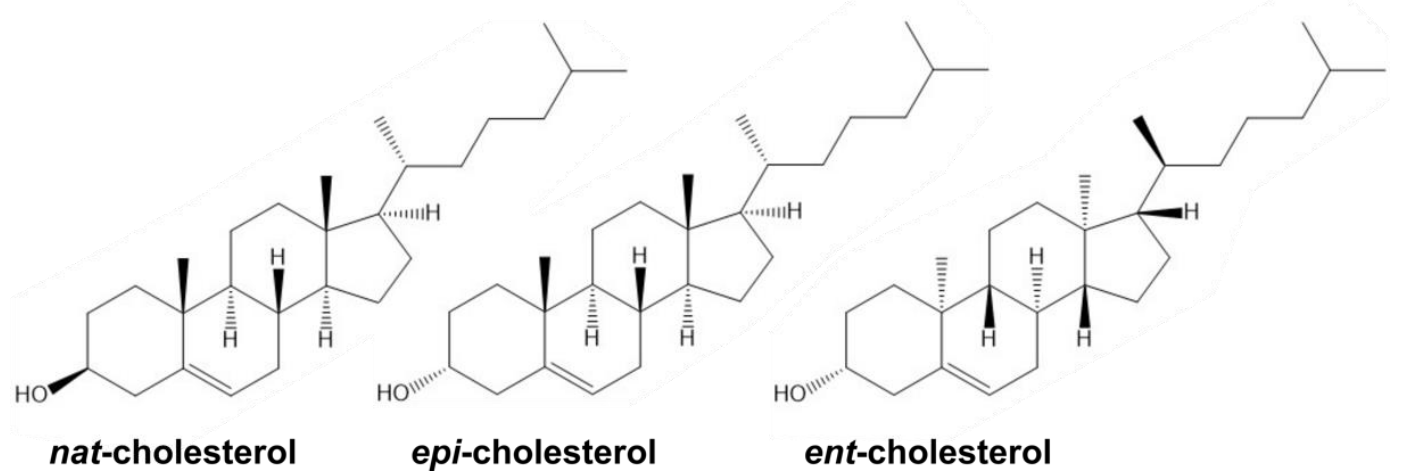

Scheme 1. Chemical structures of cholesterol isomers considered in this study.

Identification of specific cholesterol binding sites in GPCRs has been accomplished by a number of methods. Several general cholesterol interaction motifs have been proposed and identified in GPCRs by sequence alignment, ${ }^{20,21}$ including the cholesterol recognition/interaction amino acid consensus (CRAC) motif, ${ }^{22}$ constituted of the sequence $\mathrm{L} / \mathrm{V}-\mathrm{X}_{1-5}-\mathrm{Y}-\mathrm{X}_{1-5}-\mathrm{K} / \mathrm{R}$ (where $\mathrm{X}$ can represent any amino acid), and the inverted form of the CRAC motif, ${ }^{23}$ termed the CARC motif, where the central tyrosine can also be occupied by a phenylalanine residue in the CRAC domain. High-resolution structural information of multiple GPCRs $\left(\mathrm{A}_{2 \mathrm{~A}}\right.$ adenosine, ${ }^{24} \beta 1$-adrenergic, ${ }^{25} \beta 2$-adrenergic, ${ }^{26,27} 5-\mathrm{HT}_{2 \mathrm{~B}}{ }^{28}$ and metabotropic glutamate type $1^{29}$ receptors) in complex with cholesterol molecules, has revealed a number of specific cholesterol interaction sites, such as cholesterol consensus motif (CCM), a groove region between TM2 and TM4 constituted of highly conserved residues $\mathrm{Y}^{2.41}, \mathrm{~K} / \mathrm{R}^{4.39-4.43}, \mathrm{I} / \mathrm{V} / \mathrm{L}^{4.46}$ and $\mathrm{W} / \mathrm{Y}^{4.50}$ (labeled using the Ballesteros-Weinstein numbering scheme, which is a generic numbering scheme for class A GPCR's). ${ }^{27}$ Further to this, molecular dynamics (MD) simulations have become an established tool to identify high- and low-affinity cholesterol interaction sites on GPCRs and evaluate the potential consequences on protein structure and dynamics..$^{30-33}$
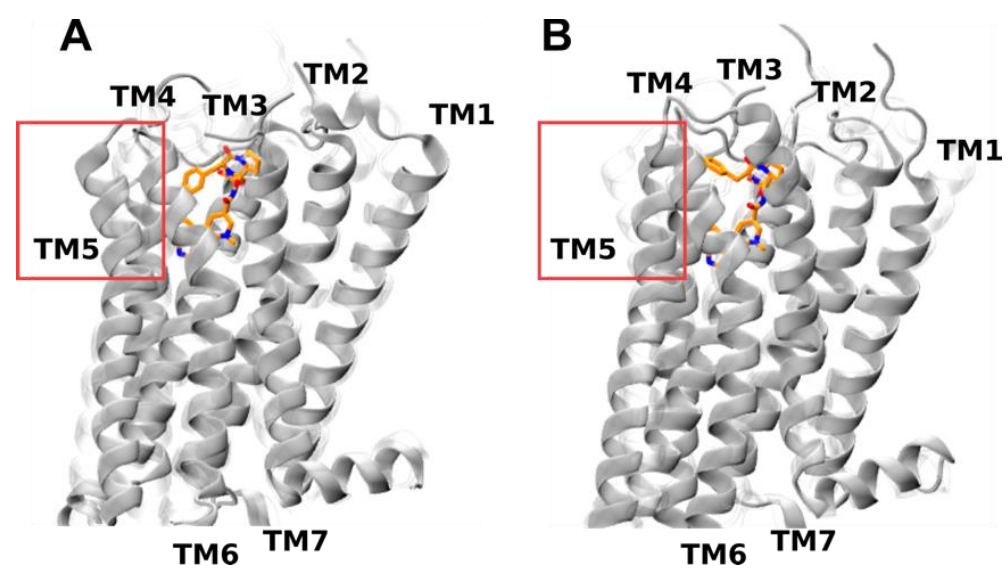

Figure 1. Crystal structures of the (A) 5- $\mathrm{HT}_{1 \mathrm{~B}}$ (PDB ID: 4IAR) and (B) 5-HT $2 \mathrm{~B}$ (PDB ID: 4IB4) receptors. Each transmembrane helix (TM) is labelled. Ergotamine is displayed with carbon, oxygen and nitrogen atoms in orange, red and blue respectively. The alternate conformations of the TM5 helix are displayed within the red boxes.

The serotonin (5-HT) receptor family spans seven receptor subfamilies $\left(5-\mathrm{HT}_{1-7}\right)$, classified by structural and functional similarities. The serotonin (5-HT) receptor family spans seven receptor subfamilies $\left(5-\mathrm{HT}_{1-}\right.$ 
7), classified by structural and functional similarities. All serotonin receptors are GPCRs, with the exception of the 5- $\mathrm{HT}_{3}$ receptor, which is a ligand-gated ion channel. 5-HT receptors have been associated with medical conditions, including neurological disorders, such as Alzheimer's disease, depression and schizophrenia. ${ }^{34,35}$

Significant experimental and computational efforts have been focused towards characterizing the functional response of the 5-HT $\mathrm{HA}_{1 \mathrm{~A}}$ receptor to cholesterol. ${ }^{36-38}$ Solubilized native hippocampal membranes exhibit diminished ligand binding, which can be restored on the addition of membrane cholesterol or its enantiomer (ent-cholesterol). ${ }^{39}$ However, replenishment with closely related molecules, such as epicholesterol (a diastereoisomer of cholesterol) ${ }^{39}$ fail to restore binding properties. Curiously, cholesterol depletion enhances ligand binding activity in neuronal cells, when examining the same agonist as prior experiments. ${ }^{40}$ Disparate effects are also observed when considering biosynthetic precursors, differing to cholesterol by a double bond, and various experimental procedures are used. ${ }^{41,42}$ Alongside this, simulation methodologies have been utilized to identify cholesterol interaction sites on homology models of the $5-\mathrm{HT}_{1 \mathrm{~A}}$ receptor, in the absence of high-resolution structural information of this subtype. ${ }^{43}$

In milestone publications, the crystal structures of related $5-\mathrm{HT}_{1 \mathrm{~B}}$ and $5-\mathrm{HT}_{2 \mathrm{~B}}$ receptors in complex with ergotamine, and dihydroergotamine in the former, were disclosed. These structures revealed insights into the molecular determinants of subtype selectivity and biased signaling (Figure 1A-B). ${ }^{44,45}$ The 5-HT receptors exhibit analogous orthosteric binding pockets, with $70 \%$ of residues completely conserved (residues 3.32, 3.37, 5.46, 6.48, 6.51, 6.52 and 7.43 in the Ballesteros-Weinstein numbering scheme), and another $10 \%$ displaying conservative mutations (3.33). As a consequence, subtype selectivity is attributed to the deviations in the extended binding pocket, constituted of residues from the second extracellular loop (ECL2) and the extracellular termini of TM3 and TM5-7. Most notably, an outward movement of TM5 in the 5- $\mathrm{HT}_{1 \mathrm{~B}}$ receptor increases the volume of the canonical binding pocket, relative to the 5- $\mathrm{HT}_{2 \mathrm{~B}}$ receptor, enabling inhabitance of bulkier ligands (Figure 1). This is demonstrated by the reported potencies of triptan molecules in wild-type 5- $\mathrm{HT}_{1 \mathrm{~B}}$ and 5- $\mathrm{HT}_{2 \mathrm{~B}}$, and 5- $\mathrm{HT}_{2 \mathrm{~B}}$ mutants, reported in the same study.

Considering the available structural information for the 5- $\mathrm{HT}_{1 \mathrm{~B}}$ and $5-\mathrm{HT}_{2 \mathrm{~B}}$ receptors, and the reported cholesterol-dependence of the closely-related $5-\mathrm{HT}_{1 \mathrm{~A}}$ receptor, we hypothesized that membrane composition may actuate the conformation of TM4-5, and the attached ECL2, in the 5-HT receptor family, which translates to diversity in the framework of the orthosteric and/or extending binding pockets. To investigate this scenario, we performed extensive unbiased MD simulations of the high-resolution crystal structures of the 5-HT $\mathrm{H}_{1 \mathrm{~B}}$ (PDB ID 4IAR) and 5- $\mathrm{HT}_{2 \mathrm{~B}}$ receptors (PDB ID 4IB4) in POPC bilayers with $0 \%$ and $30 \%$ cholesterol concentrations. We also examined ent-cholesterol and epi-cholesterol, to delineate stereospecific cholesterol binding sites, considering the response of the 5- $\mathrm{HT}_{1 \mathrm{~A}}$ receptor to these molecules. ${ }^{39}$ Previous crystallographic and NMR studies of several class A GPCRs have demonstrated ligand-specific governance of the extracellular loop structure. ${ }^{46-49}$ Thus, the 5-HT receptors of interest were simulated in the apo state, initially, to eliminate potential bias arising from the ligand identity. 


\section{METHODS}

\section{Membrane Preparation}

Bilayers containing 1-palmitoyl-2-oleoyl-sn-glycero-3-phosphocholine (POPC) molecules and natcholesterol molecules were generated using the CHARMM-GUI Membrane Builder. ${ }^{50-52}$ The cholesterolfree bilayers contained 244 POPC molecules, with 196 POPC molecules and 84 nat-cholesterol molecules used for the cholesterol-enriched bilayers content. The mixed POPC/nat-cholesterol membrane was then modified to generate additional membranes containing the ent- and epi-cholesterol. All membranes were then equilibrated using the documented CHARMM-GUI protocol, and a production run was performed for 50 ns. ${ }^{51}$ The membrane cholesterol in each bilayer was then transformed into the remaining isomers to provide three initial configurations of cholesterol in the membrane, labelled 1-3.

\section{5-HT Receptor Modeling}

The crystal structures of the 5- $\mathrm{HT}_{1 \mathrm{~B}}$ receptor (PDB ID: 4IAR) and 5- $\mathrm{HT}_{2 \mathrm{~B}}$ receptor (PDB ID: 4IB4) were used to prepare the initial models. ${ }^{28,53}$ In both cases, the third intracellular loop (residues L240 to M305 in $5-\mathrm{HT}_{1 \mathrm{~B}}$ and $\mathrm{Y} 249$ to $\mathrm{V} 313$ in $5-\mathrm{HT}_{2 \mathrm{~B}}$ ) between helices 5 and 6 was replaced by the engineered BRIL ${ }^{54}$ loop for the purpose of crystallization, and was removed. The bound agonist, ergotamine, and lipid molecules present in the crystal structure were also removed to allow for unbiased detection of lipid binding sites. Missing loops (191 to 196 and 340 to 344 in the 5-HT 1 в receptor) were replaced using the Modloop protocol, ${ }^{55}$ neutral caps were used on the termini and default protonation states were used for ionizable residues. Additional simulations were initiated with docked 5-hydroxytryptamine (5-HT), which is otherwise known as serotonin. Two conformations of serotonin were utilized to initiate independent simulations, consistent with the ergotamine binding pose observed in the crystal structure (Figure 2A). In conformation 1 (Figure 2B), the indole nitrogen of serotonin is positioned to H-bond with the T134 sidechain, and the amine tail is positioned to interact with D129. In conformation 2 (Figure 2C), serotonin is flipped so that the hydroxyl group on the six-membered indole ring can interact with the T134 side-chain, whilst the amine tail can still interact with D129.
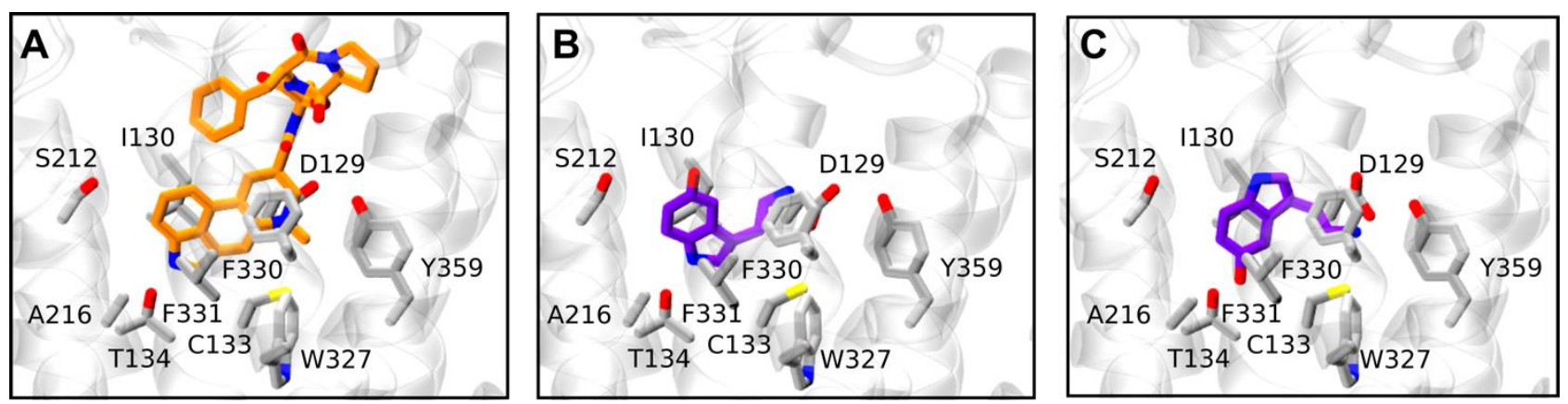

Figure 2. (A) Ergotamine binding pose (orange molecule) in the 5- $\mathrm{HT}_{1 \mathrm{~B}}$ receptor crystal structure (PDB ID 4IAR), (B) serotonin starting conformation 1, and (C) serotonin starting conformation 2. Residues forming the orthosteric binding site are shown and labelled. Oxygen and nitrogen atoms are displayed in red and blue, respectively. Carbon atoms are orange in ergotamine, purple in serotonin and grey in the receptor. 


\section{System Setup and Equilibration}

Each receptor model was aligned into the bilayer normal and inserted into the pre-equilibrated lipid bilayers (Table 1). All lipid molecules within $1.2 \AA$ of the protein were removed with final cholesterol content approximately $30 \%$ in mixed bilayers. The combined system was then solvated to produce a rectangular water box of dimensions $(92 \times 92 \times 105) \AA^{3}$. Ions were added using the Autoionize Plugin of VMD, resulting in a final concentration of $150 \mathrm{mM} .{ }^{56}$ After the removal of water molecules overlapping (distance $<1.2 \AA$ ) with the ions, lipids or protein atoms, the final system contained between 70,000 and 80,000 atoms. CHARMM22 ${ }^{54}$ parameters (with CMAP correction) were used for the protein, CHARMM36 for lipids, ${ }^{57}$ CGenFF parameters for the serotonin ligand, ${ }^{58,59}$ standard parameters for ions ${ }^{60}$ and the TIP3 $\mathrm{P}^{61}$ model for water. The modified CHARMM36 parameters by Lim et al. were used for nat-cholesterol, ent-, and epi-cholesterol molecules. ${ }^{12,62}$ NAMD2.9 was employed to calculate the dynamics of the systems throughout. ${ }^{63}$ Initially, 10,000 steps of minimization were performed to remove steric clashes, followed by the progressive removal of constraints at 500 ps intervals to allow for gradual equilibration of the system. Constraints were released in the following order: (i) bulk water and lipid tails, (ii) lipid head groups, (iii) water molecules in protein cavities, and finally, (iv) protein side chains. Unrestrained dynamics was then undertaken in the NPT ensemble. The Particle Mesh Ewald method was used for the treatment of full-system periodic electrostatic interactions; interactions were evaluated every second timestep with a value of $1 \AA$ to determine grid spacing. ${ }^{64}$ Electrostatic and van der Waals forces were calculated every timestep and up to a cutoff distance of $12 \AA$. A switching distance of $10 \AA$ was chosen to smoothly truncate the non-bonded interactions. Only atoms in a Verlet pair list within a cutoff distance of $13.5 \AA$ were considered, with the list reassigned every 20 steps. ${ }^{65}$ The SETTLE algorithm was used to constrain all bonds involving hydrogen atoms to allow the use of a 2 fs timestep. ${ }^{66}$ The NoseHoover-Langevin piston method was employed to control the pressure with a 200 fs period, 50 fs damping constant and a desired value of 1 atmosphere. ${ }^{67,68}$ The system was coupled to a Langevin thermostat to sustain a temperature of $298 \mathrm{~K}$ throughout. A summary of the simulations performed can be found in Table 1.

Table 1. Summary of simulations included in this study.

\begin{tabular}{|c|c|c|c|c|c|c|c|}
\hline \multirow[b]{2}{*}{ Receptor } & \multicolumn{3}{|c|}{ Membrane Composition } & \multirow{2}{*}{$\begin{array}{c}\text { Ligand } \\
\text { State }\end{array}$} & \multirow[t]{2}{*}{ Replica } & \multirow{2}{*}{$\begin{array}{l}\text { Simulation } \\
\text { Length (ns) }\end{array}$} & \multirow{2}{*}{$\begin{array}{c}\text { Simulation } \\
\text { Abbreviation }\end{array}$} \\
\hline & $\%$ POPC & $\%$ Cholesterol & Isomer & & & & \\
\hline \multirow[t]{11}{*}{$5-\mathrm{HT}_{1 \mathrm{~B}}$} & \multirow[t]{3}{*}{70} & \multirow[t]{3}{*}{30} & \multirow{3}{*}{$\begin{array}{l}\text { nat- } \\
\text { cholesterol }\end{array}$} & - & 1 & 600 & $\mathrm{CHL1}_{1 \mathrm{~B}}$ \\
\hline & & & & - & 2 & 600 & CHL21B \\
\hline & & & & - & 3 & 600 & $\mathrm{CHL}_{1 \mathrm{~B}}$ \\
\hline & \multirow[t]{3}{*}{70} & \multirow[t]{3}{*}{30} & \multirow{3}{*}{$\begin{array}{l}\text { ent- } \\
\text { cholesterol }\end{array}$} & - & 1 & 600 & ENT11B \\
\hline & & & & - & 2 & 600 & ENT2 $1 \mathrm{~B}$ \\
\hline & & & & - & 3 & 600 & ENT31B \\
\hline & \multirow[t]{3}{*}{70} & \multirow[t]{3}{*}{30} & \multirow{3}{*}{$\begin{array}{l}\text { epi- } \\
\text { cholesterol }\end{array}$} & - & 1 & 600 & EPI1 $_{1 \mathrm{~B}}$ \\
\hline & & & & - & 2 & 600 & EPI21B \\
\hline & & & & - & 3 & 600 & EPI3 $1 \mathrm{~B}$ \\
\hline & \multirow[t]{2}{*}{100} & \multirow[t]{2}{*}{0} & \multirow[t]{2}{*}{-} & - & 1 & 600 & $\mathrm{POPC}_{1 \mathrm{~B}}$ \\
\hline & & & & - & 2 & 600 & POPC $2_{1 \mathrm{~B}}$ \\
\hline \multirow{3}{*}{$\begin{array}{l}5-\mathrm{HT}_{1 \mathrm{~B}}+ \\
\text { Ligand }\end{array}$} & \multirow[t]{3}{*}{70} & \multirow[t]{3}{*}{30} & \multirow{3}{*}{$\begin{array}{l}\text { nat- } \\
\text { cholesterol }\end{array}$} & 1 & 1 & 600 & L1-CHL1 1B $_{18}$ \\
\hline & & & & 2 & 1 & 600 & ${\mathrm{~L} 2-\mathrm{CHL}_{1 \mathrm{~B}}}$ \\
\hline & & & & 1 & 2 & 600 & L1-CHL21B \\
\hline
\end{tabular}




\begin{tabular}{|c|c|c|c|c|c|c|c|}
\hline & & & & 2 & 2 & 600 & L2-CHL2 1 B \\
\hline & & & & 1 & 3 & 600 & L1-CHL31B \\
\hline & & & & 2 & 3 & 600 & L2-CHL3 1 B \\
\hline & 70 & 30 & & 1 & 1 & 600 & L1-ENT11B \\
\hline & & & cholesterol & 2 & 1 & 600 & L2-ENT1 1 B \\
\hline & & & & 1 & 2 & 600 & L1-ENT21B \\
\hline & & & & 2 & 2 & 600 & L2-ENT2 1 B \\
\hline & & & & 1 & 3 & 600 & L1-ENT31B \\
\hline & & & & 2 & 3 & 600 & L2-ENT3 1 B \\
\hline & 70 & 30 & ent- & 1 & 1 & 600 & L1-EPI1 $_{1 \mathrm{~B}}$ \\
\hline & & & cholesterol & 2 & 1 & 600 & L2-EPI1 $_{1 \mathrm{~B}}$ \\
\hline & & & & 1 & 2 & 600 & L1-EPI21B \\
\hline & & & & 2 & 2 & 600 & L2-EPI2 $1 \mathrm{~B}$ \\
\hline & & & & 1 & 3 & 600 & L1-EPI31B \\
\hline & & & & 2 & 3 & 600 & $\mathrm{~L}_{2-\mathrm{EPI}}{ }_{1 \mathrm{~B}}$ \\
\hline & 100 & 0 & - & 1 & 1 & 600 & L1-POPC1 $1_{1 \mathrm{~B}}$ \\
\hline & & & & 2 & 1 & 600 & L2-POPC1 $1 \mathrm{~B}$ \\
\hline & & & & 1 & 2 & 600 & L1-POPC2 $1 \mathrm{~B}$ \\
\hline & & & & 2 & 2 & 600 & L2-POPC2 $2_{1 \mathrm{~B}}$ \\
\hline & & & & 1 & 3 & 600 & L1-POPC $3_{1 \mathrm{~B}}$ \\
\hline & & & & 2 & 3 & 600 & L2-POPC3 $1 \mathrm{~B}$ \\
\hline $5-\mathrm{HT}_{2 \mathrm{~B}}$ & 70 & 30 & & & 1 & 500 & $\mathrm{CHL1}_{2 \mathrm{~B}}$ \\
\hline & & & cholesterol & & 2 & 500 & $\mathrm{CHL}_{2 \mathrm{~B}}$ \\
\hline & & & & & 3 & 500 & $\mathrm{CHL}_{2 \mathrm{~B}}$ \\
\hline & 70 & 30 & ent- & & 1 & 500 & $\mathrm{ENT1}_{2 \mathrm{~B}}$ \\
\hline & & & cholesterol & & 2 & 500 & $\mathrm{ENT}_{2 \mathrm{~B}}$ \\
\hline & & & & & 3 & 500 & ENT32B \\
\hline & 70 & 30 & & & 1 & 500 & $\mathrm{EPI}_{2 \mathrm{~B}}$ \\
\hline & & & cholesterol & & 2 & 500 & EPI22B \\
\hline & & & & & 3 & 500 & $\mathrm{EPI}_{2 \mathrm{~B}}$ \\
\hline & 100 & 0 & - & & 1 & 500 & $\mathrm{POPC}_{2 \mathrm{~B}}$ \\
\hline & & & & & 2 & 500 & $\mathrm{POPC}_{2 \mathrm{~B}}$ \\
\hline
\end{tabular}

\section{RESULTS}

\section{Specific binding of membrane components in $5-\mathrm{HT}_{1 \mathrm{~B}}$ receptor}

Cholesterol hotspots on membrane proteins are routinely identified using classical MD simulations on extended timescales, akin to the simulations presented here. A random distribution of cholesterol molecules was utilized, with simulations initiated from three different random configurations, enabling the identification of cholesterol-binding sites in an unbiased manner. To determine potential interaction sites, the spatial distribution of the cholesterol headgroups was calculated in all simulations. We focus on the extracellular leaflet in the following text (Figure 3A and S1A in the Supplementary Information).

Three high-density cholesterol regions are observed in the extracellular leaflet of the 5-HT $1 \mathrm{~B}$ receptor. S1 is a hydrophobic groove on TM2, with the polar cholesterol region also in contact distance of extracellular loop 1 (ECL1). Cholesterol molecules can also occupy a number of positions on the periphery of TM4, and in close proximity to extracellular loop 2 (ECL2). Interactions at this site typically involve two or more cholesterol molecules; this expansive region has been denoted S2. S3 encompasses the TM5-TM6 interface, with cholesterol positioning biased by the conformation of the extracellular end of these helices, as described in the following section. Out of these sites, the S2 site is reproduced in two out of three, entcholesterol simulations and all epi-cholesterol simulations. Additional positions on the receptor surface can also be occupied when the isomers are present; TM6 residues in the extracellular leaflet are one such 
site identified in three independent simulations (Figure S1). However, we note the timescales achieved in this study ( $600 \mathrm{~ns})$ prohibit exhaustive sampling of the receptor surface, and multiple association/disassociation events are not observed, hence meaningful occupation times of the cholesterol isomers in the identified hotspots cannot be extracted.
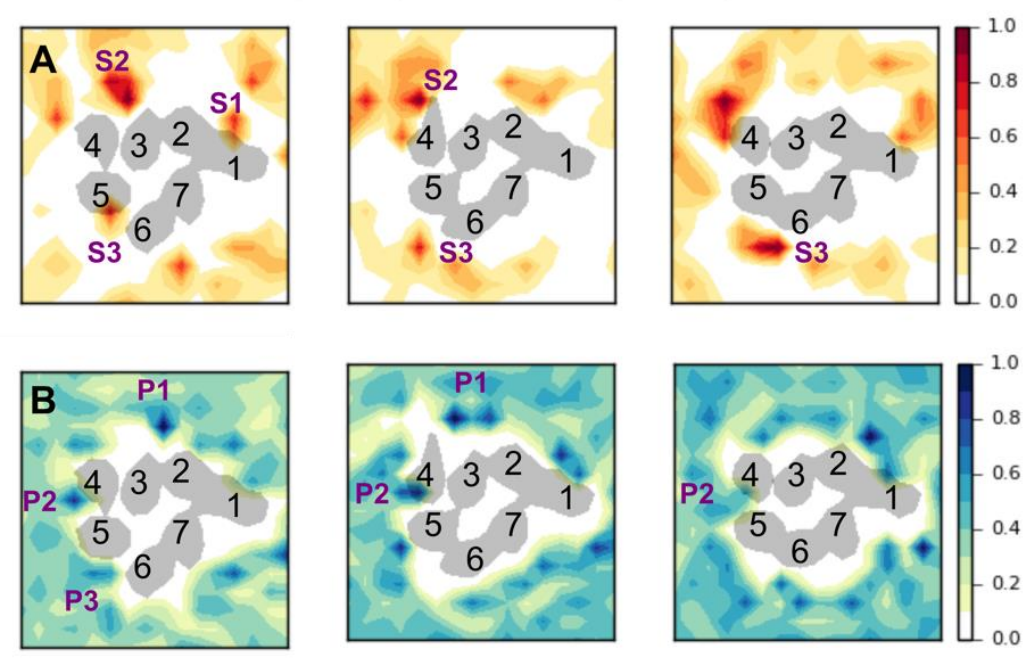

Figure 3. Interaction sites of membrane components. 2D density maps of (A) nat-cholesterol and (B) POPC, in three independent simulations of bilayers containing $30 \%$ nat-cholesterol. Bin dimensions of $4 \times 4 \AA$ are normalized so that the maximum density is 1 . Sites observed in multiple simulations (including simulations with cholesterol isomers in Figure S1) and described in the text are labelled. Transmembrane helices are numbered from 1 to 7; cholesterol and POPC sites are labelled as SX or PX respectively, where $\mathrm{X}$ is an arbitrary number to distinguish individual sites.

In addition to the cholesterol interaction sites, we sought to ascertain if specific phospholipid binding sites also exist on the receptor surface, using the same methodology (Figure 3B and S1B). We identified two reproducible high-density sites (P1 and P2) in the extracellular leaflet. P2 is of interest, present at the TM4-5 interface, reproducible in all bilayers enriched with nat-cholesterol and isomeric forms. In this site, the phospholipid headgroup intercalates between ECL2 residues, which are initially beyond reach by membrane components. Occupation of this site can be evaluated using the contact distance between POPC molecules and residue P184 (Figure S3). This is determined by calculating the distance between the center of mass of all heavy atoms in both entities and identifying the minimum. In contrast, phospholipid molecules do not penetrate the ECL2 region consistently in both POPC-only bilayer simulations. In $\mathrm{CHL}_{1 \mathrm{~B}}, \mathrm{ENT} 1_{1 \mathrm{~B}}$ and EPI $2_{1 \mathrm{~B}}$, POPC molecules are able to penetrate the TM4-TM5 interface, due to conformational changes in this region. This will be described in the following section.

\section{Cholesterol tunes the extracellular surface in $5-\mathrm{HT}_{1 \mathrm{~B}}$ receptor}

From this point forward, we refer to the second and third extracellular loops (ECL2 and ECL3) and the extracellular ends of the connected transmembrane helices (TM3-6) as the extracellular surface (ECS). The RMSD of the 5-HT 1 extracellular surface relative to initial model is given in Figure S2. The structure of the extracellular surface is a highly variable region, as shown by clustering of the ECS conformations using a $2.5 \AA$ RMSD criterion. Cluster population of the ECS is given in Table S1. Highly populated 
clusters are identified (> $70 \%$ of simulation time) in all $\mathrm{CHL}_{1 \mathrm{~B}}$ and $\mathrm{POPC}_{1 \mathrm{~B}}$ simulations. Visual inspection of the predominant clusters revealed that ECL2 can interact closely with the extracellular ends of TM5 and ECL3, or not at all, with the contact distance between hydrophobic residues V200/V201 (ECL2) and M337 (TM6) critical. We define these conformations as open or closed, pertaining to the minimum distance between all non-hydrogen atoms in V200/V201 and M337, using $4 \AA$ as a cutoff, exhibited in Figure 4A and B, respectively. The retention of such conformations, and the frequency related structural characteristics, are summarized in Table 2. The time evolution of the ECS in all simulations is reported in Figure S3-5. Cholesterol-containing bilayers can stabilize open or closed conformations of the ECS. Closed conformations of the ECS prevail in the POPC-only bilayer simulations, entering this state consistently within a period of $150 \mathrm{~ns}$. The closed state can also be stabilized by a salt-bridge between E198 and K341, as in CHL3 ${ }_{1 \mathrm{~B}}$ (Table 2). In contrast, the absence of ECL2-TM6/ELC3 interactions in several simulations can mobilize ECL3 residues; F346, for example, can either remain buried in the surrounding bilayer or protrude into the extracellular solvent. The observed separation of ECL2 and ECL3 can also be accompanied by disruption of the initial conformations of the attached helices; TM5 (T209, V210 and T213) and TM6 residues (L335 and M338) dissociate, enabling the penetration of a proximal POPC molecule into this region, as mentioned earlier. This novel conformational change can be attributed to the continued close association between TM4/ECL2 residues (in the region of P183, P184 and F185) and ECL2 residues at the opposing end, particularly N202 (Figure S5).

Table 2. Summary of dynamics in ECL2 and surrounding regions in the 5-HT $\mathrm{HB}_{1 \mathrm{~B}}$ receptor in all simulations presented. The values given are percentages of the total simulation time spent in a prototypical closed state of the EC loops. The criterion for each characteristic is given within the table.

\begin{tabular}{|c|c|c|c|c|c|}
\hline $\begin{array}{l}\text { Structural } \\
\text { Feature }\end{array}$ & $\begin{array}{c}\text { ECL2-TM6 } \\
\text { Hydrophobic } \\
\text { Interactions }\end{array}$ & $\begin{array}{l}\text { ECL2-ECL3 } \\
\text { Salt Bridge } \\
\text { Interactions }\end{array}$ & $\begin{array}{l}\text { ECL3 Membrane } \\
\text { Interactions }\end{array}$ & TM5-TM6 Interactions & $\begin{array}{l}\text { ECL2-TM4 } \\
\text { Interactions }\end{array}$ \\
\hline Criteria & $\begin{array}{c}\text { V200/V201-M337 } \\
\text { Distance } \\
<4 \AA\end{array}$ & $\begin{array}{c}\text { E198-K341 } \\
\text { Distance } \\
<4 \AA\end{array}$ & $\begin{array}{c}\text { F346 Solvent- } \\
\text { Accessible Surface } \\
\text { Area }<50 \AA^{2} \\
\end{array}$ & $\begin{array}{c}\text { T209/V210/T213-L335 } \\
\text { Distance }<5 \AA\end{array}$ & $\begin{array}{c}\text { P184-N202 } \\
\text { Distance }>4 \text { A }\end{array}$ \\
\hline $\mathrm{POPC}_{1 \mathrm{~B}}$ & 88 & 14 & 100 & 100 & 97 \\
\hline POPC $2_{1 \mathrm{~B}}$ & 82 & 13 & 100 & 82 & 96 \\
\hline $\mathrm{CHL}_{1 \mathrm{~B}}$ & 1 & 0 & 18 & 3 & 9 \\
\hline CHL2 ${ }_{1 \mathrm{~B}}$ & 3 & 0 & 5 & 100 & 59 \\
\hline $\mathrm{CHL}_{1 \mathrm{~B}}$ & 67 & 55 & 100 & 100 & 73 \\
\hline ENT1 $1_{1 \mathrm{~B}}$ & 1 & 0 & 100 & 17 & 9 \\
\hline ENT2 $_{1 \mathrm{~B}}$ & 60 & 10 & 43 & 100 & 55 \\
\hline ENT3 $3_{1 \mathrm{~B}}$ & 49 & 0 & 1 & 100 & 34 \\
\hline EPI1 $1 \mathrm{~B}$ & 35 & 2 & 13 & 100 & 56 \\
\hline $\mathrm{EPI} 2_{1 \mathrm{~B}}$ & 0 & 0 & 97 & 1 & 82 \\
\hline $\mathrm{EPI}_{1 \mathrm{~B}}$ & 81 & 1 & 0 & 100 & 69 \\
\hline
\end{tabular}

Overall, simulations with nat-cholesterol are in qualitative agreement with its enantiomer, with the ECS exhibiting variable degrees of opening, both displaying enduringly open, closed or intermediate states, with transient periods of ECS closure. Further to this, TM5 and TM6 dissociate in a similar manner. In contrast, simulations with epi-cholesterol exhibit deviant behaviour; in EPI $1_{1 \mathrm{~B}}$ and EPI $3_{1 \mathrm{~B}}$ a closed ECS 
evolves after $\sim 400 \mathrm{~ns}$, persisting for the remainder of the $600-\mathrm{ns}$ simulation. EPI $2_{1 \mathrm{~B}}$, on the other hand, exhibits open forms of ECL2-ECL3 and TM5-6 from the outset (Figure S4).
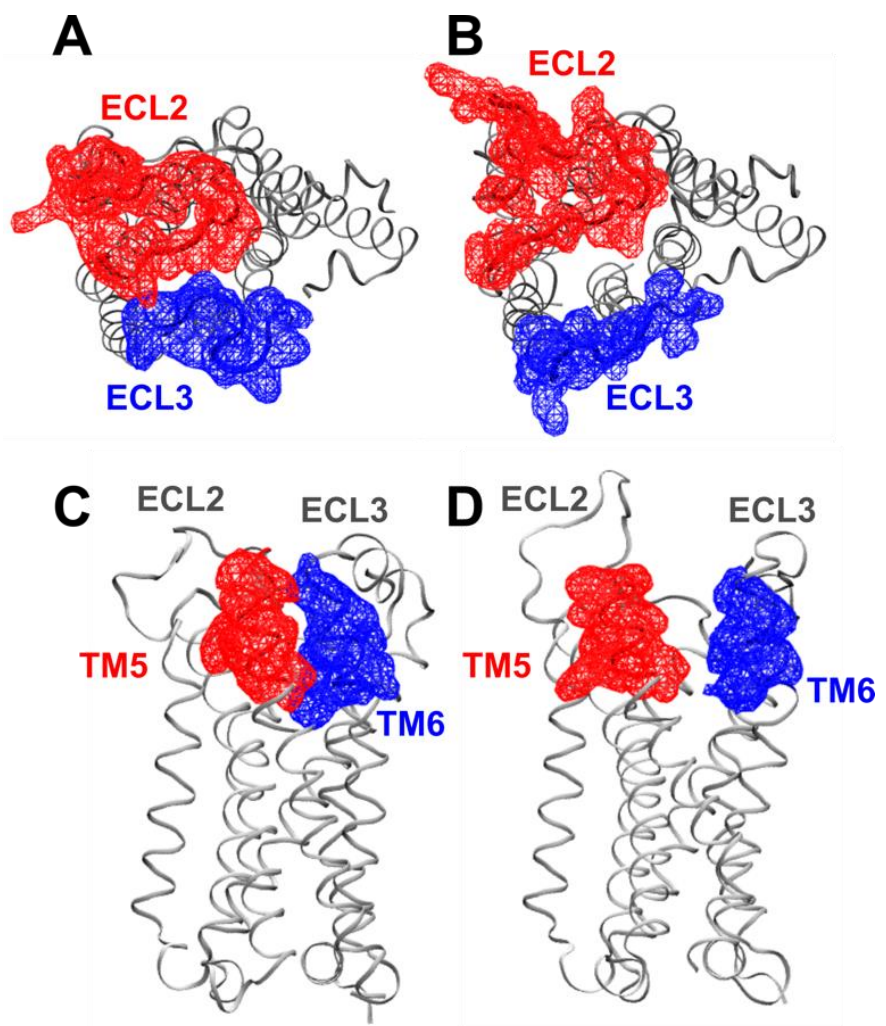

Figure 4. Dynamics of the extracellular surface. Representative structures of (A) closed (simulation $\mathrm{POPC}_{1 \mathrm{~B}}$ ) and (B) open (simulation $\mathrm{CHL}_{1 \mathrm{~B}}$ ) states of the ECS, displaying the density of residues 185204 (red) and 338-349 (blue). Representative structures of (C) closed (simulation POPC1 $1 \mathrm{~B}$ ) and (D) open (simulation CHL1 $_{1 \mathrm{~B}}$ ) TM5-TM6 helices, displaying the density of residues 205-213 (red) and 330-338 (blue). The density maps, shown as a wire mesh, are calculated using the VOLMAP plugin of VMD.

\section{Stereospecific behavior of the $\mathrm{TM} 3-4$ site in the $5-\mathrm{HT}_{1 \mathrm{~B}}$ receptor}

From this point forward, we focus on $\mathrm{CHL} 1_{1 \mathrm{~B}}, \mathrm{ENT} 1_{1 \mathrm{в}}$ and $\mathrm{EPI} 1_{1 \mathrm{1}}$ simulations, which are initiated from the same configuration of sterol molecules, displaying similar cholesterol occupancies as a result. In this case, the reported loop movements are not conserved when epi-cholesterol is present, despite occupation of molecules in the adjacent S2 site. Closure of the ECS in EPI1 at 400 ns (Figure S4), follows destabilization of the P184-N202 interaction, in the 250-300 ns time period, which is maintained in CHL1 and ENT1 (Figure 5A). P184 resides at the TM4/ECL2 boundary; throughout, multiple sterol molecules inhabit the S2 region in close proximity to P184, interacting consistently with residues from TM3 (V120, F124, S127 and T131), TM4 (I178) and ECL2 (F185).

Differences can be observed in the binding poses of individual cholesterol molecules and attributed to the differential dynamics of this region. Sterol molecules in ENT $1_{1 \mathrm{~B}}$ and EPI $1_{1 \mathrm{~B}}$ penetrate deeper in the membrane, capable of H-bonding with T131 (TM4) (Figure 5B). In the latter case, this H-bond is formed 
in the initial stages of the simulation, and epi-cholesterol remains anchored in this position for the entirety of the simulation. In this pose, the smooth face of epi-cholesterol stacks onto W174 (TM4); the hydroxyl headgroup H-bonds to T131 (TM3) and is surrounded by polar residues S127 (TM3) and S181 (TM4); the flexible tail extends to residues in TM2 (S90, V93 and L97) (Figure 5C, D). The headgroup of entcholesterol occupies the analogous region, with enhanced mobility, due to the orientation of the hydroxyl group on the rough face of cholesterol (Figure 5C, E). With this in mind, we postulate that the stability of cholesterol in this site is dependent on its exact structure, and that this region acts as a functional binding site in the $5-\mathrm{HT}_{1 \mathrm{~B}}$ receptor.
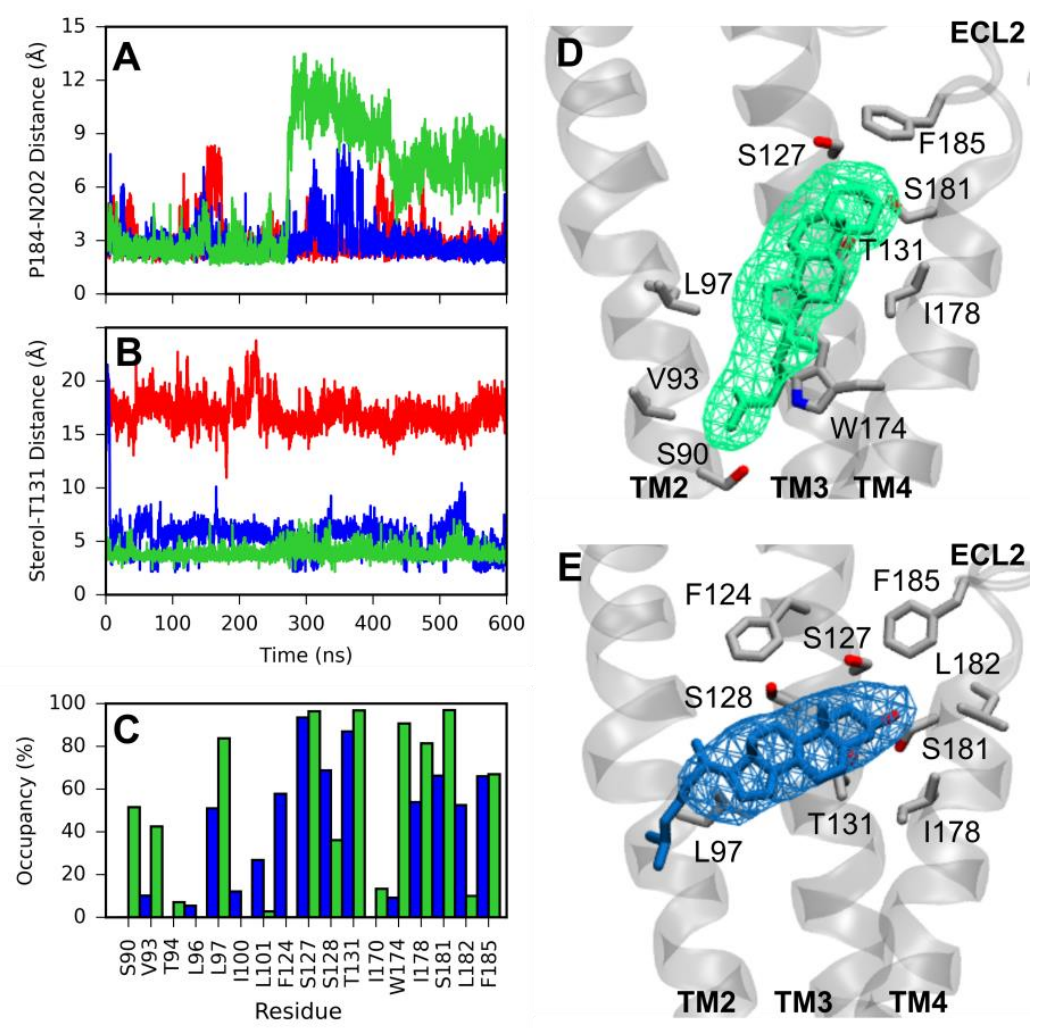

Figure 5. Comparison of 5-HT ${ }_{1 \mathrm{~B}}$ receptor dynamics in $\mathrm{CHL} 1_{1 \mathrm{~B}}$, ENT $1_{1 \mathrm{~B}}$ and $\mathrm{EPI} 1_{1 \mathrm{~B}}$ simulations. (A) Time evolution of P184-N202 contact distance, $\mathrm{CHL} 1_{1 \mathrm{~B}}, \mathrm{ENT} 1_{1 \mathrm{~B}}$ and EPI $1_{1 \mathrm{~B}}$ simulations are displayed in red, blue and green respectively. (B) Time evolution of the minimum contact distance between cholesterol hydroxyl atoms and T131, colored as in (A). (C) Contact frequency of 5-HT $\mathrm{H}_{1 \mathrm{~B}}$ residues with stable ent(blue) and epi- (green) cholesterol binding poses. Values are given as a percentage of total simulation time and calculated using a $5 \AA$ criterion. (D-E) Position of deep epi- and ent-cholesterol molecules in the S2 site. Interacting $5-\mathrm{HT}_{1 \mathrm{~B}}$ residues are shown in licorice representation in grey.

\section{Effect on ligand binding in the 5-HT $1 \mathrm{~B}$ receptor}

To discern the functional consequences of cholesterol binding to transmembrane helix 4 , and the resulting conformational changes, we focused our attention towards the extracellular ligand-binding site. In the crystal structure of the 5-HT $\mathrm{H}_{\mathrm{B}}$ receptor with bound ergotamine, which is used to construct our initial model, the planar ergoline moiety is embedded in the orthosteric binding pocket, a hydrophobic cleft composed of I130, C133, S212, A216, W327, F330 and F331 residues. Binding is stabilized by (i) a H- 
bond between the indole nitrogen of ergotamine and the T134 side-chain, and (ii) a salt-bridge interaction between the amine tail of ergotamine and D129, which in turn is reinforced by H-bonding with Y359.

Additional simulations were performed with a 5-HT molecule, commonly known as serotonin, bound in the orthosteric binding site in two alternative conformations (see Methods), consistent with the interactions observed for ergotamine in the crystal structure. To distinguish between different open and closed states of the receptor, the extracellular surface (defined as residues 184 to 205 and 337 to 349), was clustered using a 2.5 A RMSD criterion (Table S1). The position of membrane cholesterol was monitored in the most highly populated cluster. The S2 site is occupied in 10 out of 18 independent simulations containing membrane cholesterol (L1-CHL1 $1_{1 \mathrm{~B}}, \mathrm{~L} 2-\mathrm{CHL} 1_{1 \mathrm{~B}}, \mathrm{~L} 2-\mathrm{CHL} 2_{1 \mathrm{~B}}, \mathrm{~L} 2-\mathrm{ENT} 1_{1 \mathrm{~B}}, \mathrm{~L} 1-\mathrm{ENT} 2_{1 \mathrm{~B}}, \mathrm{~L} 2-$ ENT2 $2_{1 \mathrm{~B}}, \mathrm{~L} 1-\mathrm{EPI} 1_{1 \mathrm{~B}}, \mathrm{~L} 2-\mathrm{EPI} 1_{1 \mathrm{~B}}, \mathrm{~L} 1-\mathrm{EPI} 2_{1 \mathrm{~B}}$ and L1-EPI3 $\left.{ }_{1 \mathrm{~B}}\right)$. The position of the serotonin molecule was compared in ECS conformations from POPC-only simulations (denoted NoC), simulations with a mixed bilayer where $\mathrm{S} 2$ is occupied by cholesterol (denoted $\mathrm{C}_{\mathrm{S} 2}$ ) and simulations with a mixed bilayer where $\mathrm{S} 2$ is not occupied by cholesterol (denoted $\mathrm{C}_{\mathrm{NoS} 2}$ ). The density maps of cholesterol and serotonin, in the extracellular binding site are shown in Figure 6.

To illustrate the effect of cholesterol on extracellular ligands, we focus on the two most highly populated binding poses observed in the simulations, labelled Lig1 and Lig2 in Figure 6C-E. Remarkably, Lig1 is the only serotonin binding pose in the $\mathrm{C}_{\mathrm{S} 2}$ clusters. In the $\mathrm{C}_{\mathrm{NoS} 2}$ clusters, the serotonin density maximum is located in close proximity to the Lig1 position; overall, however, the serotonin position is more variable. Lig2 is a distinct maximum observed only in the NoC simulations, where serotonin resides deeper in the $5-\mathrm{HT}_{1 \mathrm{~B}}$ receptor, consistent with occupation of the orthosteric binding pocket. The contact frequency of 5$\mathrm{HT}_{1 \mathrm{~B}}$ receptor residues interacting with serotonin in conformations Lig1 and Lig2 were extracted from the L2-CHL1 $1_{1 \mathrm{~B}}$ and $\mathrm{L} 1-\mathrm{POPC} \mathrm{CB}_{1 \mathrm{~B}}$ simulations, respectively (Figure 6F-G). Important residues (contact frequency $>90 \%$ ) are shown in Table 3 . These are consistent with experimental mutagenesis studies which reveal that binding of lysergic acid diethylamide (known as LSD), serotonin and ergotamine is completely abolished in D129A, I130A, C133A, and W327A and F330A mutants. ${ }^{44,45}$ Overall, our results provide strong evidence that cholesterol binding influences the ligand binding characteristics of the 5-HT receptor. 

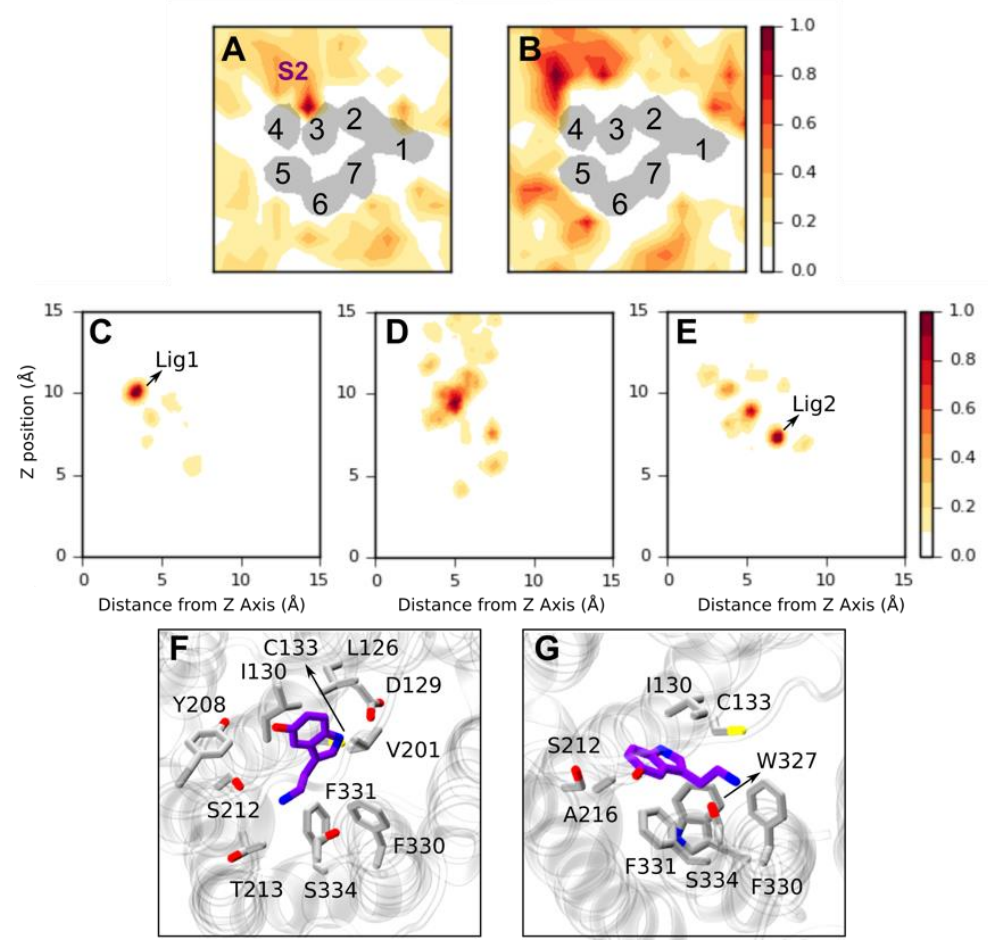

Figure 6. (A-B) Combined $2 \mathrm{D}$ density maps of the position of cholesterol isomers in $\mathrm{C}_{\mathrm{S} 2}$ and $\mathrm{C}_{\mathrm{NoS} 2}$ simulations respectively. Bin dimensions of $4 \mathrm{x} 4 \AA$ are normalized so that the maximum density is 1 . Transmembrane helices are numbered from 1 to 7 ; site $S 2$ is labelled. (C-E) Combined 2D density map of the position of the serotonin molecule in (C) $\mathrm{C}_{\mathrm{S} 2}$, (D) $\mathrm{C}_{\mathrm{NoS} 2}$ and (E) NoC simulations (defined in the main text). Throughout, the serotonin position is measured as the $\mathrm{z}$ coordinate and the distance of this from the central axis (both of the center of mass of the indole ring axis) of the simulation box. (F) Representative frame of Lig1 binding pose from the L2-CHL1 ${ }_{1 \mathrm{~B}}$ simulations and Lig2 binding pose from the L1-POPC $1 \mathrm{~B}$ simulation. Residues forming the orthosteric binding site are shown and labelled. Oxygen and nitrogen atoms are displayed in red and blue, respectively. Carbon atoms are purple in serotonin and grey in the receptor.

Table 3. Residues of 5-HT $1 \mathrm{~B}$ interacting with serotonin cluster poses Lig1 and Lig2. Residues included exhibit a contact frequency $>90 \%$, measured using a distance $5 \AA$ criterion between the heavy atoms of the protein and ligand molecules.

\begin{tabular}{|l|c|cccr|}
\hline Simulation & $\begin{array}{c}\text { Serotonin } \\
\text { Pose }\end{array}$ & \multicolumn{4}{|c|}{ Interacting Residues } \\
\hline L2-CHL1 $1 \mathrm{~B}$ & Lig1 & L126 D129 I130 C133 & V201 Y208 S212 T213 & F330 F331 S334 \\
\hline L1-POPC $_{1 \mathrm{~B}}$ & Lig2 & I130 C133 T134 & S212 & A216 W327 F330 F331 S334 \\
\hline
\end{tabular}


Table 4. Residues of 5-HT 1 в which H-bond to the hydroxyl group of cholesterol molecules in the S2 (TM4) site. H-bond frequency is given as a percentage of the cluster measured; residues with $\mathrm{H}$-bond frequency $>30 \%$ are shown.

\begin{tabular}{|c|c|c|}
\hline Simulation & Residue & H-Bond Frequency (\%) \\
\hline \multirow{2}{*}{$\mathrm{L} 1-\mathrm{CHL}_{1 \mathrm{~B}}$} & S127 & 48 \\
\hline & S128 & 64 \\
\hline $\mathrm{L} 2-\mathrm{CHL} 1_{1 \mathrm{~B}}$ & S127 & 63 \\
\hline L2-CHL2 $2_{1 \mathrm{~B}}$ & - & - \\
\hline L2-ENT1 $1_{1 \mathrm{~B}}$ & T131 & 47 \\
\hline L1-ENT2 $2_{1 \mathrm{~B}}$ & D123 & 41 \\
\hline L2-ENT2 $1 \mathrm{~B}$ & R188 & 32 \\
\hline L1-EPI1 $1 \mathrm{~B}$ & S127 & 56 \\
\hline L2-EPI1 $1 \mathrm{~B}$ & - & - \\
\hline L1-EPI2 $1 \mathrm{~B}$ & - & - \\
\hline L1-EPI3 $1 \mathrm{~B}$ & - & - \\
\hline
\end{tabular}

Examining the S2 site more closely, the cholesterol molecules are seen to penetrate deep into the upper leaflet and hydrogen bond with S127 (L1-CHL1 $1_{1 \mathrm{~B}}, \mathrm{~L} 2-\mathrm{CHL} 1_{1 \mathrm{~B}}$ and L1-EPI1 $1_{1 \mathrm{~B}}$ ) or T131 (L2-ENT1 $1_{1 \mathrm{~B}}$ ) (Table 4), in agreement with our apo state simulations. The interactions frequencies of the deep cholesterol binding sites are given for these simulations in Figure 7. In $\mathrm{CHL}_{1 \mathrm{~B}}$ simulations, the cholesterol molecule consistently interacts with L97, F124, S127, S128, T131, W174 and I178, for $>80 \%$ of the 5$\mathrm{HT}_{1 \mathrm{~B}}$ cluster frames. In addition, nat-cholesterol interacts with L182 in L1-CHL1 $1_{1 \mathrm{~B}}$ and F185 in L2$\mathrm{CHL}_{1 \mathrm{~B}}$. In L1-EPI1 $1_{1 \mathrm{~B}}$, where the hydroxyl group also H-bonds to S127, interactions with neither L182 and F185 are identified, although epi-cholesterol is more engaged with residues L101 and V175. In L2ENT $1_{1 \mathrm{~B}}$, persistent interactions ( $>80 \%$ of the cluster frames) are only observed with L97, D123, F124 and S127, highlighting the variability of ent-cholesterol in this site. This data suggests that cholesterol isomers interact differently with the TM4 surface, supporting our earlier postulate that the S2 site is stereospecific.
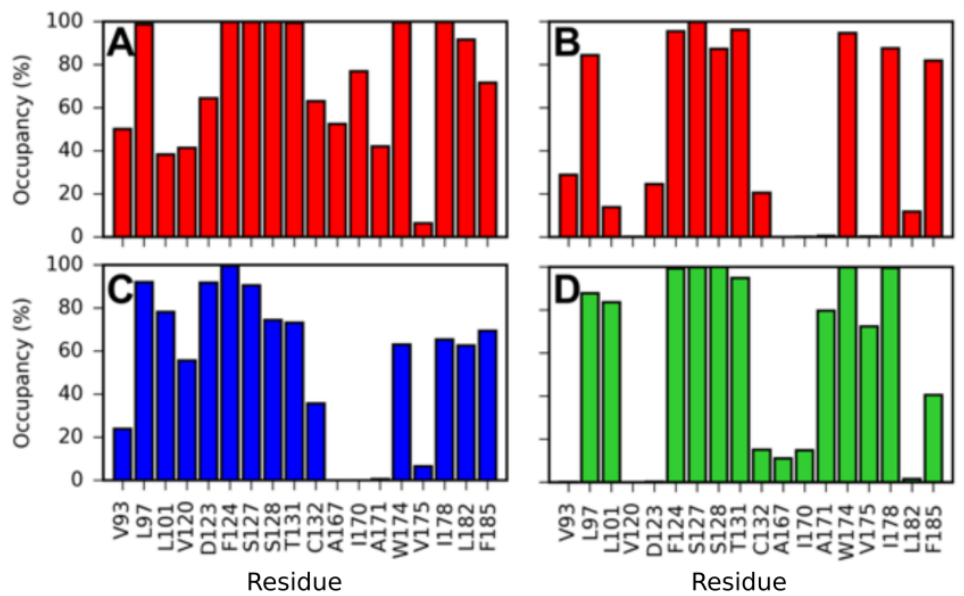

Figure 7. Contact frequency of 5- $\mathrm{HT}_{1 \mathrm{~B}}$ residues with stable nat- (red), ent- (blue) and epi- (green) cholesterol binding poses, in simulations (A) L1-CHL1 $1_{1 \mathrm{~B}}$, (B) L2-CHL1 $1_{1 \mathrm{~B}},(\mathrm{C}) \mathrm{L} 2-\mathrm{ENT} 1_{1 \mathrm{~B}}$ and L1-EPI1 $1_{1 \mathrm{~B}}$ . Values are given as a percentage of total simulation time and calculated using a $5 \AA$ criterion.

In several cases, a group of cholesterol molecules occupy the TM4 surface. This can be attributed to the high cholesterol concentration used in our simulations (30\%). Under these circumstances, cholesterol 
molecules cover a larger region of the receptor surface and it becomes difficult to delineate stable binding poses and differences between individual cholesterol isomers.

\section{Enhanced stability of ECL2 in the 5-HT $2 \mathrm{~B}$ receptor}

To determine if this mechanism of cholesterol is applicable to other 5-HT receptors, analogous simulations were performed for the 5- $\mathrm{HT}_{2 \mathrm{~B}}$ receptor, as a crystal structure is available (PDB ID 4IB4). Here, cholesterol can populate the surface of all seven transmembrane helices in the extracellular leaflet to some extent (Figure 8). Five reproducible cholesterol hotspots have been identified: L1 (TM2), L2 (TM34), L3 (TM4-5), L4 (TM5-6) and L5 (TM7-1).
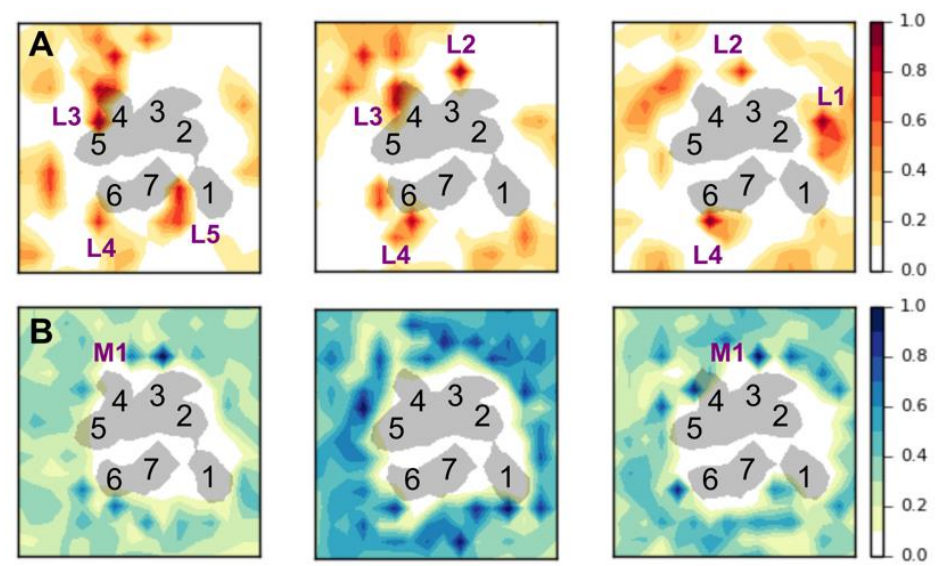

Figure 8. Interaction sites of membrane components on the 5- $\mathrm{HT}_{2 \mathrm{~B}}$ receptor. $2 \mathrm{D}$ density maps of (A) natcholesterol and (B) POPC in three independent simulations of bilayers containing 30\% cholesterol. Bin dimensions of $4 \times 4 \AA$ are normalized so that the maximum density is 1 . Sites observed in multiple simulations (including simulations with cholesterol isomers in Figure S1) and described in the text are labelled. Transmembrane helices are numbered from 1 to 7; cholesterol and POPC sites are labelled as LX or MX respectively, where $\mathrm{X}$ is an arbitrary number to distinguish individual sites.

The position of the L2 site overlaps with the S2 (TM3-4) site identified for the 5-HT $\mathrm{HT}_{1 \mathrm{~B}}$ receptor. The sequences of both receptors were aligned, and residues involved in cholesterol were compared (Figure 9). In the 5-HT $2 \mathrm{~B}$ receptor, the cluster of interacting residues (F133, I184, I188, P191 and I192) are localized at the extracellular ends of TM3 and 4 . Here, the site is $100 \%$ hydrophobic, whereas the $5-\mathrm{HT}_{1 \mathrm{~B}}$ site is $\sim 67 \%$ hydrophobic, $\sim 8 \%$ charged and $25 \%$ polar, revealing critical differences between the sites. Residues $\mathrm{S} 127, \mathrm{~S} 128$ and $\mathrm{T} 131$ in the 5- $\mathrm{HT}_{1 \mathrm{~B}}$ receptor, whose small, polar side-chains enable deep binding in the site, are equivalent to bulky, hydrophobic residues F133, L134 and L137 in the 5-HT $2 \mathrm{~B}$ receptor, prohibiting cholesterol from entering the analogous position. 
A

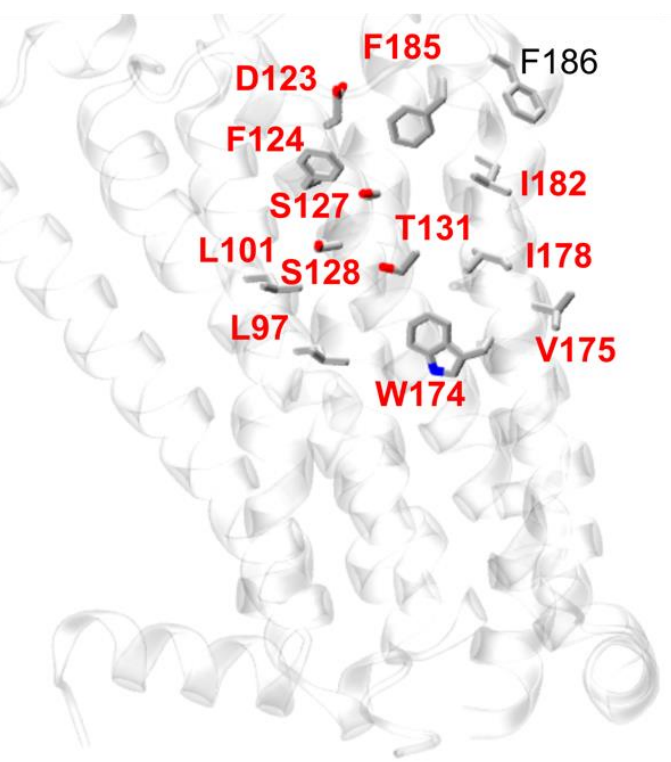

B

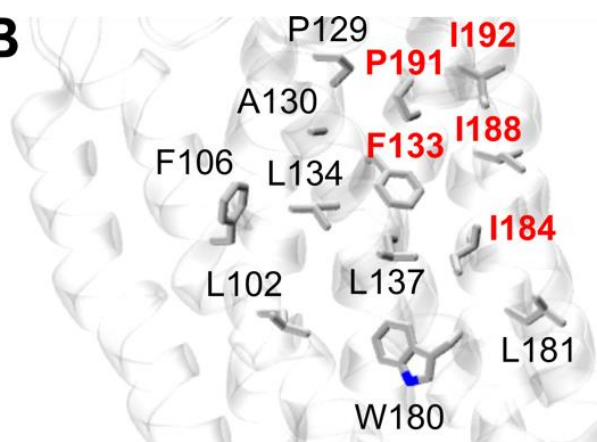

W180

Figure 9. Comparison of the TM3-4 in the (A) 5- $\mathrm{HT}_{1 \mathrm{~B}}$ and (B) 5- $\mathrm{HT}_{2 \mathrm{~B}}$ receptors. Residue side-chains are shown in licorice, with carbon, nitrogen and oxygen atoms in grey, blue and red respectively. Residues with cholesterol interaction frequencies over $80 \%$ ( $<4 \AA$ between heavy atoms) in any nat-cholesterol simulations are highlighted in red.

The consequences of cholesterol binding in such positions are ambiguous, in this case. Here, ECL2 (G194 to R213) and ECL3 (L347 to T357) do not undergo significant conformational changes. The highly flexible region of ECL2 (T197 to I205) and ECL3 is flanked by multiple anchor points to surrounding transmembrane helices: (i) a disulfide bond between C128 (TM3) and C207 (ECL2) conserved in class A GPCRs, (ii) H-bonding between the backbone oxygen atom of K193 (TM4) and the sidechain of R213 (ECL2) and vice versa, (iii) a salt-bridge between K211 (ECL2) and D351 (ECL3), and, finally (iv) a hydrophobic cluster formed between V209 (ECL2) and residues from TM3 (L132, V136), TM4 (V190) and TM5 (F217). The dynamic interactions are prevalent in the simulations irrespective of the membrane composition, negating large-scale conformational changes in the extracellular ends of TM4, TM5 and TM6 (Table 5). These native contacts are conserved in the available structures of 5- $\mathrm{HT}_{2 \mathrm{~B}}$ receptor, ${ }^{44,45,49,69}$ with the exception of $\mathrm{K} 211-\mathrm{D} 351$ in the crystal structure of the 5- $\mathrm{HT}_{2 \mathrm{~B}}$ receptor obtained using serial femtosecond crystallography at room temperature (PDB ID 4NC3), where the sidechain of K211 is unresolved. ${ }^{70}$ This is consistent with our simulation data, where a frequency of interaction approximately between 70 and $95 \%$ is recorded in this case. 
Table 5. Summary of dynamics in ECL2 and surrounding regions of the 5- $\mathrm{HT}_{2 \mathrm{~B}}$ receptor. The values given are percentages of the total simulation time spent in a prototypical closed state of the ECS. The criterion for each characteristic is given within the table. The TM3/4/5 residues specified are in close contact, forming a hydrophobic cluster; therefore, this criterion is satisfied if V209 is within $5 \AA$ of any of these residues.

\begin{tabular}{|c|c|c|c|}
\hline $\begin{array}{l}\text { Structural } \\
\text { Feature }\end{array}$ & $\begin{array}{l}\text { TM4-ECL2 } \\
\text { Salt Bridge }\end{array}$ & $\begin{array}{l}\text { ECL2-ECL3 } \\
\text { Salt Bridge }\end{array}$ & $\begin{array}{c}\text { ECL2 -TM3/4/5 } \\
\text { Hydrophobic Interactions }\end{array}$ \\
\hline Criteria & $\begin{array}{c}\text { K193-R213 } \\
\text { Distance }<3.5 \AA\end{array}$ & $\begin{array}{c}\text { K211-D351 } \\
\text { Distance }<3.5 \AA\end{array}$ & $\begin{array}{c}\text { V209- L132 (TM3)/V136 (TM3)/V190 (TM4)/F217(TM5) } \\
\text { Distance }<5.0 \AA\end{array}$ \\
\hline $\mathrm{POPC}_{2 \mathrm{~B}}$ & 100 & 77 & 99 \\
\hline $\mathrm{POPC}_{2 \mathrm{~B}}$ & 100 & 87 & 99 \\
\hline $\mathrm{CHL1}_{2 \mathrm{~B}}$ & 100 & 71 & 100 \\
\hline $\mathrm{CHL}_{2 \mathrm{~B}}$ & 100 & 86 & 100 \\
\hline $\mathrm{CHL}_{2 \mathrm{~B}}$ & 100 & 96 & 100 \\
\hline ENT12B & 100 & 68 & 100 \\
\hline $\mathrm{ENT}_{2 \mathrm{~B}}$ & 100 & 79 & 100 \\
\hline $\mathrm{ENT3}_{2 \mathrm{~B}}$ & 100 & 88 & 100 \\
\hline EPI1 $_{2 B}$ & 100 & 72 & 100 \\
\hline EPI22B & 100 & 92 & 100 \\
\hline $\mathrm{EPI}_{2 \mathrm{~B}}$ & 100 & 80 & 99 \\
\hline
\end{tabular}

\section{DISCUSSION}

The bulk of specific cholesterol interaction sites identified by structural and simulation methodologies are situated so that the hydroxyl group inhabits the headgroup region of the membrane ${ }^{8}$. However, additional buried sites have also been exposed by computation. ${ }^{71}$ In the $5-\mathrm{HT}_{2 \mathrm{~B}}$ receptor, cholesterol hotspots are shown on all of TM helices, occupying typical positions in the upper leaflet of the bilayer. In the 5-HT receptor, we detect unparalleled high occupancy of the TM4 helix by membrane cholesterol in the upper leaflet. The TM4 helix includes the CARC motif ${ }^{23}$ in the extracellular leaflet and the $\mathrm{CCM}^{27}$ in the intracellular leaflet. Our simulations reveal that of several cholesterol molecules inhabiting this area, a single molecule can penetrate a deep cholesterol binding site on the TM3/4 helices, which can contain components of both canonical interaction motifs situated in this area. This is observed in multiple independent simulations for all three stereoisomers of cholesterol examined. Cholesterol molecules are able to hydrogen-bond with S127 or T131 several residues, exhibiting differential interactions with 5$\mathrm{HT}_{1 \mathrm{~B}}$ receptor residues in each case. With this in mind, we propose this region acts as a functional binding site in the $5-\mathrm{HT}_{1 \mathrm{~B}}$ receptor, with stereospecific properties. In compliance with this, high cholesterol density on TM4 (in the extracellular leaflet) is observed in coarse-grained simulations of the closelyrelated $5-\mathrm{HT}_{1 \mathrm{~A}}$ receptor. ${ }^{31}$ This result is particularly important considering the known stereospecific requirement of cholesterol in the $5-\mathrm{HT}_{1 \mathrm{~A}}$ receptor. ${ }^{39}$

In support of this, we report reproducible conformational changes in the ECS, originating from residues in this region. The vulnerability of the TM4-ECL2 boundary in the 5- $\mathrm{HT}_{1 \mathrm{~B}}$ receptor to cholesterol binding in this region, can be accredited to the presence of multiple proline residues (P183-P184), which are unable to adopt typical secondary structural components, and thus are inherently more flexible. This motif is conserved in all 5- $\mathrm{HT}_{1}$ receptors; in 5- $\mathrm{HT}_{2}$ receptors a hydrophobic residue is inserted in the middle of the analogous proline residues (P189-V190-P181 in 5- $\mathrm{HT}_{2 \mathrm{~B}}$ ), stabilizing this area to a greater extent. Considering the importance of such residues in the adjustability of ECL2 in the 5-HT $1 \mathrm{~B}$ and 5-HT $\mathrm{H}_{2 \mathrm{~B}}$ 
receptors, it is conceivable that this region can act as a stereospecific cholesterol sensor in the 5-HT family, propagating changes through the ECS.

Interest in the behaviour of the highly variable ECS in GPCRs has grown in recent years, as a potential target for subtype-selective drugs. ${ }^{29,72,73}$ In rhodopsin, ECL2 forms a steadfast cap over the covalently bound ligand. ${ }^{74}$ However, in a number of class A GPCRs with diffusible ligands, the dependency of the ECL2 conformation on the chemical structure of the ligand has been demonstrated experimentally. In the $\beta_{2}$-adrenergic receptor, NMR spectroscopy revealed ligand-specific conformations of the ECS in the vicinity of a salt-bridge linking ECL2 and ECL3. ${ }^{46}$ In the angiotensin type II receptor, cysteine accessibility experiments disclose open and closed conformations of ECL2, which can influence the dissociation rates of bound ligands. ${ }^{47}$ In relation to 5-HT receptors, circular dichroism and steady-state fluorescence revealed variations in ECL2 conformation in the 5-HT $4 \mathrm{~A}$, resulting from binding of full, partial or inverse agonists. ${ }^{48}$ Furthermore, in the $5-\mathrm{HT}_{2 \mathrm{~B}}$ receptor, the remarkably slow dissociation rates of the archetypal hallucinogen LSD have been attributed to an ECL2 lid revealed by the high-resolution structure of this complex. ${ }^{49}$ Mutagenesis of one such residue, V209, dramatically altered LSD's binding kinetics in this case. Here, we demonstrate that cholesterol addition, depletion or substitution_is able to bias the conformational states of ECL2 in the 5-HT $1 \mathrm{~B}$, providing a potential mechanism by which cholesterol and other membrane constituents can alter the ligand-binding properties of GPCRs.

It should be noted that the exact nature of cholesterol modulation on ligand binding affinity in the 5- $\mathrm{HT}_{1 \mathrm{~B}}$ receptor cannot be ascertained from the data presented in this study. Nevertheless, our simulations expose a situation where the configuration of the extracellular binding site is altered in cholesterol-rich bilayers. In several independent simulations of the apo state, the orthosteric binding site is susceptible to lipid interactions, resulting from separation of the EC loops (ECL2 and ECL3) and the attached TM helices (TM5 and TM6). In simulations with serotonin, the ligand occupies an alternative binding site away from the orthosteric binding site, as a result of reorganization of ECL2. Coupling of the orthosteric binding pocket with the membrane milieu has been reported previously. In various cases, membrane-mediated pathways are required for ligands to circumnavigate closed ECSs, which prohibit transport between the extracellular binding pocket and solution. In the opsin receptor, TM5-6 and TM7-1 openings have been postulated to allow access to retinal, ${ }^{75-77}$ and in the human free fatty-acid receptor 1 (known as FFAR1 or GPR40), the lipophilic agonist is proposed to traverse between an opening in TM3 $-4,{ }^{78}$ both as a result of closed ECL2 conformations. Similarly, an N-terminus fold obstructs the ECS in the S1P1 receptor, indicating ligand access occurs via TM7-1. ${ }^{79}$ This multi-step process has been mapped by extensive unbiased MD simulations. ${ }^{80}$ Moreover, it has recently been reported that membrane constituents can enter the orthosteric binding pocket via similar pathways. In the adenosine $\mathrm{A}_{2 \mathrm{~A}}$ receptor, cholesterol is able to penetrate the protein core via TM5-6, effectively acting as a competitive inhibitor and abolishing binding of antagonist, ZM241385. ${ }^{81}$ Overall, these studies substantiate our proposed response to specific cholesterol binding in $5-\mathrm{HT}_{1 \mathrm{~B}}$ receptor. 
A related point to consider is the significance of the extracellular $\mathrm{N}$-terminal domain. The involvement of the GPCR N-terminus in receptor surface expression and trafficking has been studied extensively. ${ }^{82}$ This structural domain has also been implicated in regulation of ligand binding in class $\mathrm{B}^{83}$ and C GPCRs; ${ }^{84}$ several examples have also been shown for the class A receptor family. ${ }^{85,86}$ Of relevance to this study, single-residue polymorphisms (R6G and $\mathrm{E} 42 \mathrm{G}$ ) in the $\mathrm{N}$-terminus of the 5- $\mathrm{HT}_{2 \mathrm{~B}}$ receptor, were shown to increase the binding affinity of radioligand $[3 \mathrm{H}]-5$-HT amongst other effects. ${ }^{87}$ Similar outcomes were recorded when the $\mathrm{N}$-terminus was truncated. However, $\mathrm{N}$-terminus residues are absent in the structural models used in this study (1-37 in 5-HT ${ }_{1 \mathrm{~B}}$ PDB 4IAR and 1-47 in 5- $\mathrm{HT}_{2 \mathrm{~B}}$ PDB 4IB4), ${ }^{44,45}$ and in the other high-resolution structures available for these receptor types. ${ }^{49,70,88,89}$ Improvements in membrane protein crystallography have enabled the N-terminus to be resolved in a handful of rhodopsin-like GPCRs: human cannabinoid 1 (CB1) receptor, ${ }^{90}$ lysophosphatidic acid 1 (LPA1) receptor, ${ }^{91}$ sphingosine 1 -phosphate 1 receptor (S1P1), ${ }^{79} \mathrm{C}-\mathrm{X}-\mathrm{C}$ chemokine receptor type 4 (CXCR4) ${ }^{92}$ human orexin 1 receptor (OX1) ${ }^{93}$ and protease-activated receptor 1 (PAR1) ${ }^{94}$ In the future, an atomic description of the N-terminus in 5-HT receptors will be useful to further elucidate how the behaviour of the $\mathrm{N}$-terminus and extracellular surface affects ligand binding, and to what degree this is regulated by membrane cholesterol and other factors.

The indirect mechanism of cholesterol action has not been addressed thus far. The effect of cholesterol on the physical properties of model phospholipid bilayers have been studied intensively, with increased bilayer thickness and $\mathrm{S}_{\mathrm{CD}}$ order parameters, as well as decreased area per lipid, consistently reported upon cholesterol enrichment. ${ }^{95-98}$ Our previous work examined the molecular properties of nat-cholesterol, entcholesterol and epi-cholesterol in the phospholipid bilayers utilized here. ${ }^{12}$ In general, epi-cholesterol exerted slightly weaker effects on bilayer properties, yet increased the solvent-accessible surface area of POPC molecules, relative to the cholesterol-free bilayer. In contrast, cholesterol-rich bilayers containing nat- and ent-cholesterol decreased this property. Considering this, we cannot completely rule out an indirect effect of cholesterol on the dynamics of the 5- $\mathrm{HT}_{1 \mathrm{~B}}$ receptor. It is apparent, however, that the decisive conformational changes reported can be rationalized by stereospecific binding of cholesterol molecules to the receptor surface.

Finally, we acknowledge the increasing abundance of literature concerning the effect of cholesterol on the oligomerization properties of GPCRs. For example, coarse-grained MD simulations have shown that the dimer interface in the $\beta 2$-adrenergic receptor is altered when cholesterol concentration is increased. ${ }^{99}$ Similar conclusions have since been reported for the $5-\mathrm{HT}_{1 \mathrm{~A}}$ receptor ${ }^{100}$ and chemokine receptor type 4 using comparable methodologies. ${ }^{101}$ The interrelationship between membrane cholesterol, receptor dimerization and the conformation of the extracellular surface may prove interesting in future studies.

\section{CONCLUSIONS}

In the current study, over $25 \mu$ s of unbiased MD simulations has been used to explore the relationship between membrane cholesterol in the 5-HT receptor family, specifically the 5- $\mathrm{HT}_{1 \mathrm{~B}}$ and 5- $\mathrm{HT}_{2 \mathrm{~B}}$ receptors. Our data suggests that the stability of the extracellular surface is subtype-dependent; the conformation of 
ECL2 in the 5- $\mathrm{HT}_{2 \mathrm{~B}}$ receptor is maintained by a number of salt-bridges and hydrophobic interactions with sequentially distant regions of the protein. In the absence of such interactions in the 5-HT $1 \mathrm{~B}$ receptor, ECL2 is unmistakably more mobile, populating a number of distinct conformations. In the latter case, we provide evidence that fluctuations in ECL2 are governed by occupation of the TM3 and TM4 surfaces by cholesterol molecules in the extracellular leaflet. Mobile residues at the TM4-ECL2 boundary are critical in this respect, interacting with both membrane cholesterol and residues at the other extreme of ECL2. Comparative analysis of cholesterol isomers demonstrates differential binding to this site, suggesting structural rearrangements in this region may be influenced by stereospecific binding of cholesterol. In addition, distinctive binding poses of serotonin are observed in simulations where cholesterol is bound in the suggested TM4 site, and where the TM4 site is unoccupied, providing a direct relationship between occupation of this site and ligand binding characteristics of the 5- $\mathrm{HT}_{1 \mathrm{~B}}$ receptor. This data contributes to our understanding of how cholesterol and other membrane components modulate receptor function and might aid the development of targeted therapies of GPCRs, required for the treatment of numerous neurological disorders, such as depression and anxiety.

\section{AUTHOR INFORMATION}

Corresponding Authors: C.Domene@bath.ac.uk

\section{Funding Sources}

This study was supported by the Biotechnology and Biological Sciences Research Council and Pfizer (BB/L015269/1) through a CASE studentship to V. Oakes.

\section{ACKNOWLEDGMENTS}

We acknowledge PRACE for awarding us access to computational resources in ARCHER the UK National Supercomputing Service (http://www.archer.ac.uk), the PDC Centre for High Performance Computing (PDC-HPC), CINECA under the ISCRA initiative, CSCS in Switzerland and Jülich Supercomputing Centre (Germany).

\section{ABBREVIATIONS}

Serotonin/5-hydroxytryptamine (5-HT); G-protein coupled receptors (GPCRs); transmembrane helix (TM); molecular dynamics (MD); cholesterol recognition amino acid consensus (CRAC); cholesterol consensus motif (CCM); inverted form of the CRAC motif (CARC); extracellular loop 1 (ECL1); extracellular loop 2 (ECL2); extracellular loop 3 (ECL3); extracellular surface (ECS)

\section{REFERENCES}

(1) Sriram, K.; Insel, P. A. G Protein-Coupled Receptors as Targets for Approved Drugs: How Many Targets and How Many Drugs? Molecular Pharmacology 2018, 93 (4), 251.

(2) Paila, Y. D.; Chattopadhyay, A. In Cholesterol Binding and Cholesterol Transport Proteins: Structure and Function in Health and Disease; Harris, J. R., Ed.; Springer: New York, 2010; Vol. 51. 
(3) Harikumar, K. G.; Puri, V.; Singh, R. D.; Hanada, K.; Pagano, R. E.; Miller, L. J. Differential effects of modification of membrane cholesterol and sphingolipids on the conformation, function, and trafficking of the $\mathrm{G}$ protein-coupled cholecystokinin receptor. Journal of Biological Chemistry 2005, 280 (3), 2176.

(4) Dawaliby, R.; Trubbia, C.; Delporte, C.; Masureel, M.; Van Antwerpen, P.; Kobilka, B. K.; Govaerts, C. Allosteric regulation of $G$ protein-coupled receptor activity by phospholipids. Nature Chemical Biology 2016, 12 (1), 35.

(5) Pucadyil, T. J.; Chattopadhyay, A. Cholesterol modulates ligand binding and G-protein coupling to serotonin $(1 \mathrm{~A})$ receptors from bovine hippocampus. Biochimica Et Biophysica Acta-Biomembranes 2004, 1663 (1-2), 188.

(6) Pucadyil, T. J.; Chattopadhyay, A. Cholesterol modulates the antagonist-binding function of hippocampal serotonin(1A) receptors. Biochimica Et Biophysica Acta-Biomembranes 2005, 1714 (1), 35.

(7) Chattopadhyay, A.; Jafurulla, M.; Kalipatnapu, S.; Pucadyil, T. J.; Harikumar, K. G. Role of cholesterol in ligand binding and G-protein coupling of serotonin(1A) receptors solubilized from bovine hippocampus. Biochemical and Biophysical Research Communications 2005, 327 (4), 1036.

(8) Gimpl, G. Interaction of G protein coupled receptors and cholesterol. Chemistry and Physics of Lipids 2016, 199, 61.

(9) Levitan, I.; Singh, D. K.; Rosenhouse-Dantsker, A. Cholesterol binding to ion channels. Frontiers in Physiology 2014, 5, 14.

(10) Xu, X. L.; London, E. The effect of sterol structure on membrane lipid domains reveals how cholesterol can induce lipid domain formation. Biochemistry 2000, 39 (5), 843.

(11) Gimpl, G.; Burger, K.; Fahrenholz, F. Cholesterol as modulator of receptor function. Biochemistry 1997, 36 (36), 10959.

(12) Oakes, V.; Domene, C. Stereospecific Interactions of Cholesterol in a Model Cell Membrane: Implications for the Membrane Dipole Potential. The Journal of Membrane Biology 2018, 251 (3), 507.

(13) Westover, E. J.; Covey, D. F. The enantiomer of cholesterol. Journal of Membrane Biology 2004, 202 (2), 61.

(14) Addona, G. H.; Sandermann, H.; Kloczewiak, M. A.; Miller, K. W. Low chemical specificity of the nicotinic acetylcholine receptor sterol activation site. Biochimica Et Biophysica Acta-Biomembranes 2003, 1609 (2), 177.

(15) Sooksawate, T.; Simmonds, M. A. Effects of membrane cholesterol on the sensitivity of the GABA(A) receptor to GABA in acutely dissociated rat hippocampal neurones. Neuropharmacology 2001, 40 (2), 178.

(16) Romanenko, V. G.; Rothblat, G. H.; Levitan, I. Sensitivity of volume-regulated anion current to cholesterol structural analogues. Journal of General Physiology 2004, 123 (1), 77.

(17) D'Avanzo, N.; Hyrc, K.; Enkvetchakul, D.; Covey, D. F.; Nichols, C. G. Enantioselective Protein-Sterol Interactions Mediate Regulation of Both Prokaryotic and Eukaryotic Inward Rectifier K+ Channels by Cholesterol. Plos One 2011, 6 (4), 7.

(18) Bukiya, A. N.; Belani, J. D.; Rychnovsky, S.; Dopico, A. M. Specificity of cholesterol and analogs to modulate BK channels points to direct sterol-channel protein interactions. Journal of General Physiology 2011, 137 (1), 93.

(19) Picazo-Juarez, G.; Romero-Suarez, S.; Nieto-Posadas, A.; Llorente, I.; Jara-Oseguera, A.; Briggs, M.; Mclntosh, T. J.; Simon, S. A.; Ladron-de-Guevara, E.; Islas, L. D.et al. 
Identification of a Binding Motif in the S5 Helix That Confers Cholesterol Sensitivity to the TRPV1 Ion Channel. Journal of Biological Chemistry 2011, 286 (28), 24966.

(20) Jafurulla, M.; Tiwari, S.; Chattopadhyay, A. Identification of cholesterol recognition amino acid consensus (CRAC) motif in G-protein coupled receptors. Biochemical and biophysical research communications 2011, 404 (1), 569.

(21) Fantini, J.; Barrantes, F. J. How cholesterol interacts with membrane proteins: an exploration of cholesterol-binding sites including CRAC, CARC, and tilted domains. Frontiers in Physiology 2013, 4, 9.

(22) Li, H.; Papadopoulos, V. Peripheral-type benzodiazepine receptor function in cholesterol transport. Identification of a putative cholesterol recognition/interaction amino acid sequence and consensus pattern. Endocrinology 1998, 139 (12), 4991.

(23) Baier, C. J.; Fantini, J.; Barrantes, F. J. Disclosure of cholesterol recognition motifs in transmembrane domains of the human nicotinic acetylcholine receptor. Sci. Rep. 2011, 1.

(24) Liu, W.; Chun, E.; Thompson, A. A.; Chubukov, P.; Xu, F.; Katritch, V.; Han, G. W.; Roth, C. B.; Heitman, L. H.; Ijzerman, A. P.et al. Structural Basis for Allosteric Regulation of GPCRs by Sodium Ions(). Science (New York, N.y.) 2012, 337 (6091), 232.

(25) Warne, T.; Moukhametzianov, R.; Baker, J. G.; Nehme, R.; Edwards, P. C.; Leslie, A. G.; Schertler, G. F.; Tate, C. G. The structural basis for agonist and partial agonist action on a beta(1)-adrenergic receptor. Nature 2011, 469 (7329), 241.

(26) Cherezov, V.; Rosenbaum, D. M.; Hanson, M. A.; Rasmussen, S. G. F.; Thian, F. S.; Kobilka, T. S.; Choi, H.-J.; Kuhn, P.; Weis, W. I.; Kobilka, B. K.et al. High Resolution Crystal Structure of an Engineered Human $\beta(2)$-Adrenergic $G$ protein-Coupled Receptor. Science (New York, N.Y.) 2007, 318 (5854), 1258.

(27) Hanson, M. A.; Cherezov, V.; Roth, C. B.; Griffith, M. T.; Jaakola, V.-P.; Chien, E. Y. T.; Velasquez, J.; Kuhn, P.; Stevens, R. C. A specific cholesterol binding site is established by the $2.8 \AA$ structure of the human $\beta(2)$-adrenergic receptor in an alternate crystal form. Structure (London, England : 1993) 2008, 16 (6), 897.

(28) Wang, C.; Jiang, Y.; Ma, J.; Wu, H.; Wacker, D.; Katritch, V.; Han, G. W.; Liu, W.; Huang, X. P.; Vardy, E.et al. Structural basis for molecular recognition at serotonin receptors. Science 2013, 340 (6132), 610.

(29) Wu, H.; Wang, C.; Gregory, K. J.; Han, G. W.; Cho, H. P.; Xia, Y.; Niswender, C. M.; Katritch, V.; Meiler, J.; Cherezov, V.et al. Structure of a Class C GPCR Metabotropic Glutamate Receptor 1 Bound to an Allosteric Modulator. Science 2014, 344 (6179), 58.

(30) Sengupta, D.; Chattopadhyay, A. Molecular dynamics simulations of GPCR-cholesterol interaction: An emerging paradigm. Biochimica Et Biophysica Acta-Biomembranes 2015, 1848 (9), 1775.

(31) Sengupta, D.; Prasanna, X.; Mohole, M.; Chattopadhyay, A. Exploring GPCR-Lipid Interactions by Molecular Dynamics Simulations: Excitements, Challenges, and the Way Forward. Journal of Physical Chemistry B 2018, 122 (22), 5727.

(32) Oakes, V.; Domene, C. In Computational Tools for Chemical Biology; The Royal Society of Chemistry, 2018.

(33) Jorgensen, C.; Oakes, V.; Domene, C. In Membrane Organization and Dynamics; Chattopadhyay, A., Ed.; Springer-Verlag Berlin: Berlin, 2017; Vol. 20.

(34) Ramírez, M. J. 5-HT(6 )receptors and Alzheimer's disease. Alzheimer's Research \& Therapy 2013, 5 (2), 15.

(35) Akhondzadeh, S. The 5-HT hypothesis of schizophrenia. IDrugs : the investigational drugs journal 2001, 4 (3), 295. 
(36) Saxena, R.; Chattopadhyay, A. Membrane cholesterol stabilizes the human serotonin(1A) receptor. Biochimica Et Biophysica Acta-Biomembranes 2012, 1818 (12), 2936.

(37) Shrivastava, S.; Pucadyil, T. J.; Paila, Y. D.; Ganguly, S.; Chattopadhyay, A. Chronic cholesterol depletion using statin impairs the function and dynamics of human serotonin(1A) receptors. Biochemistry 2010, 49 (26), 5426.

(38) Paila, Y. D.; Murty, M. R.; Vairamani, M.; Chattopadhyay, A. Signaling by the human serotonin(1A) receptor is impaired in cellular model of Smith-Lemli-Opitz Syndrome. Biochim Biophys Acta 2008, 1778 (6), 1508.

(39) Jafurulla, M.; Rao, B. D.; Sreedevi, S.; Ruysschaert, J. M.; Covey, D. F.; Chattopadhyay, A. Stereospecific requirement of cholesterol in the function of the serotonin1A receptor. Biochim Biophys Acta 2014, 1838 (1 Pt B), 158.

(40) Prasad, R.; Paila, Y. D.; Chattopadhyay, A. Membrane cholesterol depletion enhances ligand binding function of human serotonin(1A) receptors in neuronal cells. Biochemical and Biophysical Research Communications 2009, 390 (1), 93.

(41) Singh, P.; Saxena, R.; Paila, Y. D.; Jafurulla, M.; Chattopadhyay, A. Differential effects of cholesterol and desmosterol on the ligand binding function of the hippocampal serotonin(1A) receptor: Implications in desmosterolosis. Biochimica Et Biophysica ActaBiomembranes 2009, 1788 (10), 2169.

(42) Singh, P.; Jafurulla, M.; Paila, Y. D.; Chattopadhyay, A. Desmosterol replaces cholesterol for ligand binding function of the serotonin(1A) receptor in solubilized hippocampal membranes: Support for nonannular binding sites for cholesterol? Biochimica Et Biophysica Acta-Biomembranes 2011, 1808 (10), 2428.

(43) Sengupta, D.; Chattopadhyay, A. Identification of Cholesterol Binding Sites in the Serotonin(1A) Receptor. Journal of Physical Chemistry B 2012, 116 (43), 12991.

(44) Wacker, D.; Wang, C.; Katritch, V.; Han, G. W.; Huang, X. P.; Vardy, E.; McCorvy, J. D.; Jiang, Y.; Chu, M. H.; Siu, F. Y.et al. Structural Features for Functional Selectivity at Serotonin Receptors. Science 2013, 340 (6132), 615.

(45) Wang, C.; Jiang, Y.; Ma, J. M.; Wu, H. X.; Wacker, D.; Katritch, V.; Han, G. W.; Liu, W.; Huang, X. P.; Vardy, E.et al. Structural Basis for Molecular Recognition at Serotonin Receptors. Science 2013, 340 (6132), 610.

(46) Bokoch, M. P.; Zou, Y. Z.; Rasmussen, S. G. F.; Liu, C. W.; Nygaard, R.; Rosenbaum, D. M.; Fung, J. J.; Choi, H. J.; Thian, F. S.; Kobilka, T. S.et al. Ligand-specific regulation of the extracellular surface of a G-protein-coupled receptor. Nature 2010, 463 (7277), 108.

(47) Unal, H.; Jagannathan, R.; Bhat, M. B.; Karnik, S. S. Ligand-specific Conformation of Extracellular Loop-2 in the Angiotensin II Type 1 Receptor. Journal of Biological Chemistry 2010, 285 (21), 16341.

(48) Baneres, J. L.; Mesnier, D.; Martin, A.; Joubert, L.; Dumuis, A.; Bockaert, J. Molecular characterization of a purified 5-HT4 receptor - A structural basis for drug efficacy. Journal of Biological Chemistry 2005, 280 (21), 20253.

(49) Wacker, D.; Wang, S.; McCorvy, J. D.; Betz, R. M.; Venkatakrishnan, A. J.; Levit, A.; Lansu, K.; Schools, Z. L.; Che, T.; Nichols, D. E.et al. Crystal Structure of an LSD-Bound Human Serotonin Receptor. Cell 2017, 168 (3), 377.

(50) Jo, S.; Kim, T.; Iyer, V. G.; Im, W. CHARMM-GUI: a web-based graphical user interface for CHARMM. Journal of computational chemistry 2008, 29 (11), 1859.

(51) Jo, S.; Lim, J. B.; Klauda, J. B.; Im, W. CHARMM-GUI Membrane Builder for Mixed Bilayers and Its Application to Yeast Membranes. Biophysical Journal 2009, 97 (1), 50. Wu, E. L.; Cheng, X.; Jo, S.; Rui, H.; Song, K. C.; Dávila-Contreras, E. M.; Qi, Y.; Lee, J.; Monje-Galvan, V.; Venable, R. M. CHARMM-GUI Membrane Builder toward realistic 
biological membrane simulations. Journal of computational chemistry 2014, 35 (27), 1997.

(53) Wacker, D.; Wang, C.; Katritch, V.; Han, G. W.; Huang, X.-P.; Vardy, E.; McCorvy, J. D.; Jiang, Y.; Chu, M.; Siu, F. Y.et al. Structural Features for Functional Selectivity at Serotonin Receptors. Science 2013, 340 (6132), 615.

(54) Li, H.; Robertson, A. D.; Jensen, J. H. Very fast empirical prediction and rationalization of protein pKa values. Proteins 2005, 61 (4), 704.

(55) Fiser, A.; Sali, A. ModLoop: automated modeling of loops in protein structures. Bioinformatics 2003, 19 (18), 2500.

(56) Humphrey, W.; Dalke, A.; Schulten, K. VMD: Visual molecular dynamics. Journal of Molecular Graphics 1996, 14 (1), 33.

(57) Klauda, J. B.; Venable, R. M.; Freites, J. A.; O'Connor, J. W.; Tobias, D. J.; MondragonRamirez, C.; Vorobyov, I.; MacKerell Jr, A. D.; Pastor, R. W. Update of the CHARMM allatom additive force field for lipids: validation on six lipid types. The journal of physical chemistry B 2010, 114 (23), 7830.

(58) Vanommeslaeghe, K.; MacKerell, A. D. Automation of the CHARMM General Force Field (CGenFF) I: Bond Perception and Atom Typing. Journal of Chemical Information and Modeling 2012, 52 (12), 3144.

(59) Vanommeslaeghe, K.; Raman, E. P.; MacKerell, A. D. Automation of the CHARMM General Force Field (CGenFF) II: Assignment of Bonded Parameters and Partial Atomic Charges. Journal of Chemical Information and Modeling 2012, 52 (12), 3155.

(60) Noskov, S. Y.; Berneche, S.; Roux, B. Control of ion selectivity in potassium channels by electrostatic and dynamic properties of carbonyl ligands. Nature 2004, 431 (7010), 830.

(61) Jorgensen, W. L.; Chandrasekhar, J.; Madura, J. D.; Impey, R. W.; Klein, M. L. Comparison of simple potential functions for simulating liquid water. The Journal of chemical physics 1983, 79 (2), 926.

(62) Lim, J. B.; Rogaski, B.; Klauda, J. B. Update of the Cholesterol Force Field Parameters in CHARMM. Journal of Physical Chemistry B 2012, 116 (1), 203.

(63) Phillips, J. C.; Braun, R.; Wang, W.; Gumbart, J.; Tajkhorshid, E.; Villa, E.; Chipot, C.; Skeel, R. D.; Kale, L.; Schulten, K. Scalable molecular dynamics with NAMD. Journal of computational chemistry 2005, 26 (16), 1781.

(64) Darden, T.; York, D.; Pedersen, L. Particle mesh Ewald: An N·log(N) method for Ewald sums in large systems. The Journal of chemical physics 1993, 98 (12), 10089.

(65) Verlet, L. Computer" experiments" on classical fluids. I. Thermodynamical properties of Lennard-Jones molecules. Physical review 1967, 159 (1), 98.

(66) Miyamoto, S.; Kollman, P. A. SETTLE: an analytical version of the SHAKE and RATTLE algorithm for rigid water models. J. Comput. Chem. 1992, 13 (8), 952.

(67) Feller, S. E.; Zhang, Y.; Pastor, R. W.; Brooks, B. R. Constant pressure molecular dynamics simulation: the Langevin piston method. The Journal of chemical physics 1995, 103 (11), 4613.

(68) Martyna, G. J.; Tobias, D. J.; Klein, M. L. Constant pressure molecular dynamics algorithms. The Journal of Chemical Physics 1994, 101 (5), 4177.

(69) Ishchenko, A.; Wacker, D.; Kapoor, M.; Zhang, A.; Han, G. W.; Basu, S.; Patel, N.; Messerschmidt, M.; Weierstall, U.; Liu, W.et al. Structural insights into the extracellular recognition of the human serotonin $2 \mathrm{~B}$ receptor by an antibody. Proceedings of the National Academy of Sciences of the United States of America 2017, 114 (31), 8223. 
(70) Liu, W.; Wacker, D.; Gati, C.; Han, G. W.; James, D.; Wang, D. J.; Nelson, G.; Weierstall, U.; Katritch, V.; Barty, A.et al. Serial Femtosecond Crystallography of G Protein-Coupled Receptors. Science 2013, 342 (6165), 1521.

(71) Genheden, S.; Essex, J. W.; Lee, A. G. G protein coupled receptor interactions with cholesterol deep in the membrane. Biochimica Et Biophysica Acta-Biomembranes 2017, 1859 (2), 268.

(72) Wheatley, M.; Wootten, D.; Conner, M. T.; Simms, J.; Kendrick, R.; Logan, R. T.; Poyner, D. R.; Barwell, J. Lifting the lid on GPCRs: the role of extracellular loops. British Journal of Pharmacology 2012, 165 (6), 1688.

(73) Conn, P. J.; Christopoulos, A.; Lindsley, C. W. Allosteric modulators of GPCRs: a novel approach for the treatment of CNS disorders. Nature Reviews Drug Discovery 2009, 8 (1), 41.

(74) Palczewski, K.; Kumasaka, T.; Hori, T.; Behnke, C. A.; Motoshima, H.; Fox, B. A.; Le Trong, I.; Teller, D. C.; Okada, T.; Stenkamp, R. E.et al. Crystal structure of rhodopsin: A G protein-coupled receptor. Science 2000, 289 (5480), 739.

(75) Park, J. H.; Scheerer, P.; Hofmann, K. P.; Choe, H. W.; Ernst, O. P. Crystal structure of the ligand-free G-protein-coupled receptor opsin. Nature 2008, 454 (7201), 183.

(76) Hildebrand, P. W.; Scheerer, P.; Park, J. H.; Choe, H. W.; Piechnick, R.; Ernst, O. P.; Hofmann, K. P.; Heck, M. A Ligand Channel through the G Protein Coupled Receptor Opsin. Plos One 2009, 4 (2), 9.

(77) Piechnick, R.; Ritter, E.; Hildebrand, P. W.; Ernst, O. P.; Scheerer, P.; Hofmann, K. P.; Heck, M. Effect of channel mutations on the uptake and release of the retinal ligand in opsin. Proceedings of the National Academy of Sciences of the United States of America 2012, 109 (14), 5247.

(78) Srivastava, A.; Yano, J.; Hirozane, Y.; Kefala, G.; Gruswitz, F.; Snell, G.; Lane, W.; Ivetac, A.; Aertgeerts, K.; Nguyen, J.et al. High-resolution structure of the human GPR40 receptor bound to allosteric agonist TAK-875. Nature 2014, 513 (7516), 124.

(79) Hanson, M. A.; Roth, C. B.; Jo, E. J.; Griffith, M. T.; Scott, F. L.; Reinhart, G.; Desale, H.; Clemons, B.; Cahalan, S. M.; Schuerer, S. C.et al. Crystal Structure of a Lipid G ProteinCoupled Receptor. Science 2012, 335 (6070), 851.

(80) Stanley, N.; Pardo, L.; De Fabritiis, G. The pathway of ligand entry from the membrane bilayer to a lipid G protein-coupled receptor. Scientific Reports 2016, 6, 9.

(81) Guixa-Gonzalez, R.; Albasanz, J. L.; Rodriguez-Espigares, I.; Pastor, M.; Sanz, F.; MartiSolano, M.; Manna, M.; Martinez-Seara, H.; Hildebrand, P. W.; Martin, M.et al. Membrane cholesterol access into a G-protein-coupled receptor. Nature Communications 2017, 8, 12.

(82) Dong, C. M.; Filipeanu, C. M.; Duvernay, M. T.; Wu, G. Y. Regulation of G protein-coupled receptor export trafficking. Biochimica Et Biophysica Acta-Biomembranes 2007, 1768 (4), 853.

(83) Neumann, J. M.; Couvineau, A.; Murail, S.; Lacapere, J. J.; Jamin, N.; Laburthe, M. Class-B GPCR activation: is ligand helix-capping the key? Trends in Biochemical Sciences 2008, 33 (7), 314.

(84) Kniazeff, J.; Prezeau, L.; Rondard, P.; Pin, J. P.; Goudet, C. Dimers and beyond: The functional puzzles of class C GPCRs. Pharmacology \& Therapeutics 2011, 130 (1), 9.

(85) Srinivasan, S.; Lubrano-Berthelier, C.; Govaerts, C.; Picard, F.; Santiago, P.; Conklin, B. R.; Vaisse, C. Constitutive activity of the melanocortin-4 receptor is maintained by its $\mathrm{N}$ terminal domain and plays a role in energy homeostasis in humans. Journal of Clinical Investigation 2004, 114 (8), 1158. 
(86) Ersoy, B. A.; Pardo, L.; Zhang, S. M.; Thompson, D. A.; Millhauser, G.; Govaerts, C.; Vaisse, C. Mechanism of N-terminal modulation of activity at the melanocortin-4 receptor GPCR. Nature Chemical Biology 2012, 8 (8), 725.

(87) Belmer, A.; Doly, S.; Setola, V.; Banas, S. M.; Moutkine, I.; Boutourlinsky, K.; Kenakin, T.; Maroteaux, L. Role of the N-Terminal Region in G Protein-Coupled Receptor Functions: Negative Modulation Revealed by 5-HT2B Receptor Polymorphisms. Molecular Pharmacology 2014, 85 (1), 127.

(88) Garcia-Nafria, J.; Nehme, R.; Edwards, P. C.; Tate, C. G. Cryo-EM structure of the serotonin 5-HT1B receptor coupled to heterotrimeric G(o). Nature 2018, 558 (7711), 620.

(89) McCorvy, J. D.; Wacker, D.; Wang, S.; Agegnehu, B.; Liu, J.; Lansu, K.; Tribo, A. R.; Olsen, R. H. J.; Che, T.; Jin, J.et al. Structural determinants of 5-HT2B receptor activation and biased agonism. Nature Structural \& Molecular Biology 2018, 25 (9), 787.

(90) Hua, T.; Vemuri, K.; Pu, M. C.; Qu, L.; Han, G. W.; Wu, Y. R.; Zhao, S. W.; Shui, W. Q.; Li, S. S.; Korde, A.et al. Crystal Structure of the Human Cannabinoid Receptor CB1. Cell 2016, $167(3), 750$.

(91) Chrencik, J. E.; Roth, C. B.; Terakado, M.; Kurata, H.; Omi, R.; Kihara, Y.; Warshaviak, D.; Nakade, S.; Asmar-Rovira, G.; Mileni, M.et al. Crystal Structure of Antagonist Bound Human Lysophosphatidic Acid Receptor 1. Cell 2015, 161 (7), 1633.

(92) Qin, L.; Kufareva, I.; Holden, L. G.; Wang, C.; Zheng, Y.; Zhao, C. X.; Fenalti, G.; Wu, H. X.; Han, G. W.; Cherezov, V.et al. Crystal structure of the chemokine receptor CXCR4 in complex with a viral chemokine. Science 2015, 347 (6226), 1117.

(93) Yin, J.; Babaoglu, K.; Brautigam, C. A.; Clark, L.; Shao, Z. H.; Scheuermann, T. H.; Harrell, C. M.; Gotter, A. L.; Roecker, A. J.; Winrow, C. J.et al. Structure and ligand-binding mechanism of the human OX1 and OX2 orexin receptors. Nature Structural \& Molecular Biology 2016, 23 (4), 293.

(94) Zhang, C.; Srinivasan, Y.; Arlow, D. H.; Fung, J. J.; Palmer, D.; Zheng, Y. W.; Green, H. F.; Pandey, A.; Dror, R. O.; Shaw, D. E.et al. High-resolution crystal structure of human protease-activated receptor 1. Nature 2012, 492 (7429), 387.

(95) McConnell, H. M.; Radhakrishnan, A. Condensed complexes of cholesterol and phospholipids. Biochimica Et Biophysica Acta-Biomembranes 2003, 1610 (2), 159.

(96) Jedlovszky, P.; Mezei, M. Effect of cholesterol on the properties of phospholipid membranes. 1. Structural features. Journal of Physical Chemistry B 2003, 107 (22), 5311.

(97) de Meyer, F.; Smit, B. Effect of cholesterol on the structure of a phospholipid bilayer. Proceedings of the National Academy of Sciences of the United States of America 2009, 106 (10), 3654.

(98) Rog, T.; Pasenkiewicz-Gierula, M.; Vattulainen, I.; Karttunen, M. Ordering effects of cholesterol and its analogues. Biochimica Et Biophysica Acta-Biomembranes 2009, 1788 (1), 97.

(99) Prasanna, X.; Chattopadhyay, A.; Sengupta, D. Cholesterol Modulates the Dimer Interface of the beta(2)-Adrenergic Receptor via Cholesterol Occupancy Sites. Biophysical Journal 2014, 106 (6), 1290.

(100) Prasanna, X.; Sengupta, D.; Chattopadhyay, A. Cholesterol-dependent Conformational Plasticity in GPCR Dimers. Scientific Reports 2016, 6, 12.

(101) Pluhackova, K.; Gahbauer, S.; Kranz, F.; Wassenaar, T. A.; Bockmann, R. A. Dynamic Cholesterol-Conditioned Dimerization of the G Protein Coupled Chemokine Receptor Type 4. Plos Computational Biology 2016, 12 (11), 25. 
Authors are required to submit a graphic entry for the Table of Contents (TOC) that, in conjunction with the manuscript title, should give the reader a representative idea of one of the following: A key structure, reaction, equation, concept, or theorem, etc., that is discussed in the manuscript. Consult the journal's Instructions for Authors for TOC graphic specifications.

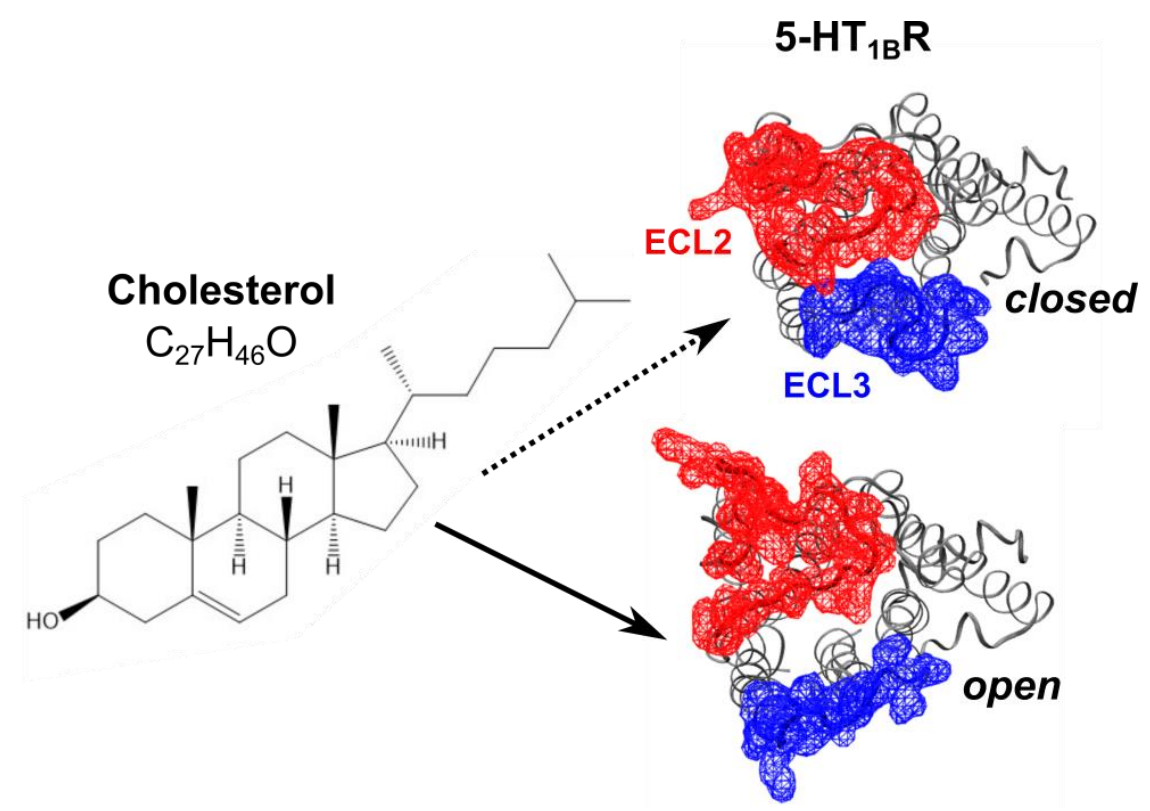

